\title{
Satellite observations and modeling of transport in the upper troposphere through the lower mesosphere during the 2006 major stratospheric sudden warming
}

\author{
G. L. Manney ${ }^{1,2}$, R. S. Harwood ${ }^{3}$, I. A. MacKenzie ${ }^{3}$, K. Minschwaner ${ }^{2}$, D. R. Allen ${ }^{4}$, M. L. Santee ${ }^{1}$, K. A. Walker ${ }^{5,6}$, \\ M. I. Hegglin ${ }^{5}$, A. Lambert ${ }^{1}$, H. C. Pumphrey ${ }^{3}$, P. F. Bernath ${ }^{7,6}$, C. D. Boone ${ }^{6}$, M. J. Schwartz ${ }^{1}$, N. J. Livesey ${ }^{1}$, \\ W. H. Daffer ${ }^{1}$, and R. A. Fuller ${ }^{1}$ \\ ${ }^{1}$ Jet Propulsion Laboratory, California Institute of Technology, Pasadena, CA, USA \\ ${ }^{2}$ New Mexico Institute of Mining and Technology, Socorro, NM, USA \\ ${ }^{3}$ University of Edinburgh, Edinburgh, UK \\ ${ }^{4}$ Dordt College, Sioux Center, IA, USA \\ ${ }^{5}$ University of Toronto, Toronto, Ontario, Canada \\ ${ }^{6}$ University of Waterloo, Waterloo, Ontario, Canada \\ ${ }^{7}$ University of York, Heslington, York, UK
}

Received: 28 February 2009 - Published in Atmos. Chem. Phys. Discuss.: 16 April 2009

Revised: 29 June 2009 - Accepted: 8 July 2009 - Published: 20 July 2009

\begin{abstract}
An unusually strong and prolonged stratospheric sudden warming (SSW) in January 2006 was the first major SSW for which globally distributed long-lived trace gas data are available covering the upper troposphere through the lower mesosphere. We use Aura Microwave Limb Sounder (MLS), Atmospheric Chemistry Experiment-Fourier Transform Spectrometer (ACE-FTS) data, the SLIMCAT Chemistry Transport Model (CTM), and assimilated meteorological analyses to provide a comprehensive picture of transport during this event. The upper tropospheric ridge that triggered the SSW was associated with an elevated tropopause and layering in trace gas profiles in conjunction with stratospheric and tropospheric intrusions. Anomalous poleward transport (with corresponding quasi-isentropic troposphereto-stratosphere exchange at the lowest levels studied) in the region over the ridge extended well into the lower stratosphere. In the middle and upper stratosphere, the breakdown of the polar vortex transport barrier was seen in a signature of rapid, widespread mixing in trace gases, including $\mathrm{CO}$, $\mathrm{H}_{2} \mathrm{O}, \mathrm{CH}_{4}$ and $\mathrm{N}_{2} \mathrm{O}$. The vortex broke down slightly later and more slowly in the lower than in the middle stratosphere. In the middle and lower stratosphere, small remnants with
\end{abstract}

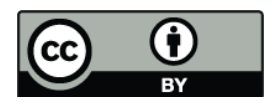

Correspondence to: G. L. Manney (gloria.1.manney@jpl.nasa.gov) trace gas values characteristic of the pre-SSW vortex lingered through the weak and slow recovery of the vortex. The upper stratospheric vortex quickly reformed, and, as enhanced diabatic descent set in, $\mathrm{CO}$ descended into this strong vortex, echoing the fall vortex development. Trace gas evolution in the SLIMCAT CTM agrees well with that in the satellite trace gas data from the upper troposphere through the middle stratosphere. In the upper stratosphere and lower mesosphere, the SLIMCAT simulation does not capture the strong descent of mesospheric $\mathrm{CO}$ and $\mathrm{H}_{2} \mathrm{O}$ values into the reformed vortex; this poor CTM performance in the upper stratosphere and lower mesosphere results primarily from biases in the diabatic descent in assimilated analyses.

\section{Introduction}

A strong and prolonged Arctic major stratospheric sudden warming (SSW) began in January 2006 (e.g., Hoffmann et al., 2007; Siskind et al., 2007; Manney et al., 2008b). Coy et al. (2009) showed evidence suggesting that this SSW was forced by waves propagating from an upper tropospheric ridge that developed over the North Atlantic after mid-January. Analysis of satellite temperature measurements extending into the mesosphere showed that the stratopause completely broke down during the SSW, then reformed at

Published by Copernicus Publications on behalf of the European Geosciences Union. 
very high $(>75 \mathrm{~km})$ altitude afterward (Siskind et al., 2007; Manney et al., 2008a,b). Not only was the 2006 major SSW one of the strongest and most prolonged on record, and thus of particular interest in its own right, but also, prior to this event, insufficient trace gas data were available to provide a complete picture of middle atmosphere transport during a major warming.

A few detailed modeling studies of transport during major SSWs have been done (e.g., Manney et al., 2005b; Konopka et al., 2005), focusing on the middle and lower stratosphere, but trace gas data to assess model performance were largely unavailable. Leovy et al. (1985) used Limb Infrared Monitor of the Stratosphere (LIMS) ozone $\left(\mathrm{O}_{3}\right)$ data to illuminate some aspects of transport in the middle and lower stratosphere during the February 1979 major SSW, and Manney et al. (1994a) compared LIMS $\mathrm{O}_{3}$ with mechanistic model simulations to further investigate the origins of the observed features. Randall et al. (2005) reconstructed a "proxy" $\mathrm{O}_{3}$ field from observations from several solar occultation instruments to compare with the model results of Manney et al. (2005b) during the Southern Hemisphere (SH) major SSW in September 2002. Lahoz et al. (1994), Manney et al. (1994c), and Sutton et al. (1994) showed some aspects of stratospheric transport during minor SSWs using Upper Atmosphere Research Satellite (UARS) Microwave Limb Sounder (MLS), Cryogenic Limb Array Etalon Spectrometer (CLAES), and Improved Stratospheric And Mesospheric Sounder (ISAMS) long-lived trace gas data (including nitrous oxide, $\mathrm{N}_{2} \mathrm{O}$, and water vapour, $\mathrm{H}_{2} \mathrm{O}$ ). Allen et al. (1999) showed observed patterns of transport in ISAMS carbon monoxide (CO) during a minor SSW in January 1992, including descent of mesospheric CO into the stratospheric vortex.

These observational studies have been limited by several factors: There were no major SSWs when UARS MLS, CLAES, or ISAMS (instruments with hemispheric daily coverage) were operating, and although the UARS Halogen Occultation Experiment (HALOE) solar occultation instrument continued to provide data until late 2005 , it had very poor high latitude coverage during winter. Thus no extensive measurements of long-lived tracers (e.g., $\mathrm{N}_{2} \mathrm{O}$, methane $\left(\mathrm{CH}_{4}\right)$, $\mathrm{H}_{2} \mathrm{O}, \mathrm{CO}$ ) have been available during previous major SSWs. Transport studies using $\mathrm{O}_{3}$ are limited to the middle and lower stratosphere, where dynamical timescales are close to or shorter than its chemical lifetime. Even in these regions, however, chemical effects can play a substantial role in $\mathrm{O}_{3}$ evolution (e.g., heterogeneous chemistry in the lower stratosphere (e.g., WMO, 2007); formation of "low-ozone pockets" in the middle stratosphere (e.g., Manney et al., 1995)).

Even more critically, data to provide a complete picture of transport in the upper troposphere through the lower mesosphere have been unavailable until recently. CO (a good tracer of upper stratosphere/lower mesosphere (USLM) transport) was available from ISAMS for only a portion of one Northern Hemisphere $(\mathrm{NH})$ and one $\mathrm{SH}$ winter. $\mathrm{O}_{3}$ (which becomes a good tracer in the upper tropo- sphere/lower stratosphere, UTLS) from LIMS and UARS MLS and CLAES did not extend into the lowermost stratosphere (lower limits were $\sim 100 \mathrm{hPa}$ ). Similarly, measurements of $\mathrm{CH}_{4}$ and $\mathrm{N}_{2} \mathrm{O}$ from CLAES were limited to the stratosphere. Also, it has recently become apparent that the atmosphere is closely coupled from the upper troposphere through the mesosphere (e.g., Thompson et al., 2005; Shepherd, 2007; Pancheva et al., 2008). This is particularly evident during major SSWs as planetary-scale waves propagating from the upper troposphere into the polar upper stratosphere drive the breakdown of the stratospheric vortex, and result in changes in gravity-wave propagation and breaking, leading to cooling of the mesosphere (related to anomalous gravity wave filtering) and enhanced radiative cooling near the stratopause (Hoffmann et al., 2007; Siskind et al., 2007; Coy et al., 2009; Manney et al., 2008b, and references therein). Full understanding of how these dynamical and radiative changes affect transport requires the study of trace gas distributions over the entire altitude range from the upper troposphere to the mesosphere; such comprehensive datasets are only now becoming available from recent satellite measurements.

With the launch of NASA's Earth Observing System (EOS) Aura satellite in July 2004, carrying an advanced MLS instrument (Waters et al., 2006), we now have near-global daily measurements of several long-lived tracers of transport. Detailed information on transport from the lower stratosphere through the lower mesosphere is provided by MLS $\mathrm{H}_{2} \mathrm{O}, \mathrm{N}_{2} \mathrm{O}$ and $\mathrm{CO}$, and in the UTLS by MLS $\mathrm{O}_{3}, \mathrm{HNO}_{3}$, $\mathrm{H}_{2} \mathrm{O}$ and CO. In addition to MLS, the Atmospheric Chemistry Experiment-Fourier Transform Spectrometer (ACEFTS) solar occultation instrument (Bernath et al., 2005), which has been taking data since early 2004, measures a large suite of species including long-lived tracers such as $\mathrm{CH}_{4}$ that are not measured by MLS. While ACE-FTS provides observations at no more than 15 longitudes around a single latitude in each hemisphere per day, its orbit is designed to provide good coverage of polar regions in winter, thus much information on transport can be extracted from these sparse data by mapping in vortex-centered coordinates (e.g., Manney et al., 1999b, 2007).

Manney et al. (2008b) described the synoptic evolution in the middle stratosphere through the lower mesosphere during the 2006 SSW. The event fulfilled major warming conditions (zonal mean zonal wind and temperature gradient reversal north of $60^{\circ} \mathrm{N}$ at $10 \mathrm{hPa}$ ) on 21 January, and was preceded by a strong minor warming that started around 8 January. Upper stratospheric winds reversed around 9 January and remained easterly in the polar regions until early February, after which a very strong westerly jet reformed around $45^{\circ} \mathrm{N}$ and moved poleward. Though a very strong upper stratospheric vortex reformed quickly after the warming, the middle stratospheric vortex recovered very slowly, and the lower stratospheric vortex remained weak and ill-defined for the remainder of the winter. As is common after early (December or January) 
major SSWs (Manney et al., 2005a, and references therein), the final warming was slow and late, with $10 \mathrm{hPa}$ zonal mean winds not reversing permanently until early May. Initial examinations of Arctic trace gas data from MLS and ACE-FTS (Manney et al., 2008a; Jin et al., 2009), reports of anomalous stratospheric effects of energetic particle precipitation in 2006 after the SSW (Randall et al., 2006), and a low column $\mathrm{O}_{3}$ event associated with the upper tropospheric ridge forcing the 2006 SSW (Keil et al., 2007) all point to highly anomalous transport throughout the upper troposphere, stratosphere and mesosphere during the 2006 Arctic winter associated with the SSW.

Here we use Aura MLS and ACE-FTS data, along with diagnostics calculated from assimilated meteorological analyses, to detail large-scale transport in the entire region covering the upper troposphere through the lower mesosphere during the 2005-2006 NH winter, focusing on the SSW. Observed transport is compared with simulations using the SLIMCAT Chemistry Transport Model (CTM) (Chipperfield, 2006); in the UTLS, additional comparisons are made with high-resolution Lagrangian calculations. Section 2 provides a description of the datasets and models used. In Sect. 3, we provide an overview of transport in the middle and lower stratosphere in the context of the vortex evolution described above, and relate these results to those from previous studies. We then turn to examination of the regions that have not been studied in any detail before: Data were not available for comprehensive studies of the USLM until recently; Sect. 4 provides a detailed description of observed and modeled transport in this region. Section 5 gives a view of modeled and observed transport in the UTLS made possible by recent satellite data extending to these levels, focusing on the dynamical processes forcing the SSW. A summary and conclusions are given in Sect. 6.

\section{Data, analysis, and models}

\subsection{Meteorological data and analysis}

The primary meteorological dataset used here is the Goddard Earth Observing System Version 5.10 (GEOS-5) analysis from NASA's Global Modeling and Assimilation Office (GMAO), described by Reinecker et al. (2008). GEOS-5 uses the Gridpoint Statistical Analysis method of Wu et al. (2002), a 3-D-Variational system, and a six-hour analysis window. The interface between the observations and the general circulation model (GCM) is performed using the incremental analysis update (IAU) approach (Bloom et al., 1996), which avoids shocking the model, thus producing smoother analyses. GEOS-5 analyses are provided on 72 model levels from the surface to $0.01 \mathrm{hPa}(\sim 75 \mathrm{~km})$, on a $0.5^{\circ}$ latitude by $0.6667^{\circ}$ longitude grid.

European Centre for Medium-Range Weather Forecasts (ECMWF) analyses are used to drive the SLIMCAT CTM.
ECMWF analyses are from a 4D-Var system based on a spectral general circulation model (e.g., Simmons et al., 2005). Beginning in February 2006, ECMWF fields are from a T799 ( $\sim 0.3^{\circ}$ horizontal resolution)/91-level system with a model top at $80 \mathrm{~km}$ (e.g., Untch et al., 2006, and other ECMWF newsletters, available at http://www.ecmwf.int/publications/ newsletters/); before February 2006, the operational data are from a T512/60-level model with a top at $60 \mathrm{~km}$.

Manney et al. (2008b) provide further details of the GEOS-5 and ECMWF analyses and describe large, but differing, biases in the ECMWF and GEOS-5 analyses with respect to satellite data during and following the 2006 SSW.

Derived meteorological products (DMPs) for ACE and MLS have been calculated from the GEOS-5 analyses, as described in detail by Manney et al. (2007). These products comprise meteorological variables (winds, temperature, potential vorticity (PV)) and fields calculated from them (e.g., equivalent latitude (EqL) and tropopause heights) interpolated to the observation locations and times of the satellite instruments. The DMPs are calculated operationally for both instruments and MLS DMPs are publicly available (Manney et al., 2007). We use the GEOS-5 DMPs for ACE and MLS to map the data into EqL/potential temperature $(\theta)$ coordinates and to provide information on the location of measurements with respect to the vortex for vortex averages. Details of EqL mapping and vortex averaging using the DMPs are as described by Manney et al. (2007).

The evolution of the trace gas fields is compared with effective diffusivity $\left(\mathrm{K}_{\mathrm{eff}}\right)$, calculated as described by Allen and Nakamura (2001). $K_{\text {eff }}$, which is expressed here as lognormalized equivalent length, provides a measure of mixing and transport barriers (e.g., Haynes and Shuckburgh, 2000a,b; Allen and Nakamura, 2001; Tan et al., 2004), with low values representing transport barriers and high values representing strong mixing. The $\mathrm{K}_{\mathrm{eff}}$ calculations for this period are taken from a long-term run of the advectiondiffusion model of Allen and Nakamura (2001) that was driven with Met Office analyses (Swinbank and O'Neill, 1994; Swinbank et al., 2002, 2004) until 13 March 2006 (the time of a major change in the Met Office assimilation system) and with GEOS-4 analyses after that date. The Met Office analyses come from a system with a lower model top $(\sim 60 \mathrm{~km})$ than the GEOS and ECMWF analyses, and are thus expected to be less reliable in the upper stratosphere.

\subsection{Satellite datasets: MLS and ACE-FTS}

Table 1 lists the MLS and ACE-FTS species used (shown and/or discussed) here, with validation paper citations and regions of the middle atmosphere (UTLS, lower stratosphere (LS), middle stratosphere (MS), USLM) in which each is most useful as a tracer of transport.

MLS measures millimeter- and submillimeter-wavelength thermal emission from the limb of Earth's atmosphere. Detailed information on the measurement technique and the 
Table 1. MLS and ACE-FTS species used in regions of the middle atmosphere. Middle atmosphere regions are abbreviated as: Lower stratosphere (LS), middle stratosphere (MS), upper stratosphere/lower mesosphere (USLM), upper troposphere/lower stratosphere (UTLS).

\begin{tabular}{llll}
\hline Species & Instrument & Regions & Citation \\
\hline $\mathrm{CH}_{4}$ & ACE-FTS & LS, MS, USLM & De Maziere et al. (2008) \\
$\mathrm{CO}$ & ACE-FTS & MS, USLM & Clerbaux et al. (2008) \\
& MLS & MS, USLM & Pumphrey et al. (2007) \\
$\mathrm{H}_{2} \mathrm{O}$ & ACE-FTS & LS, MS, USLM & Carleer et al. (2008) \\
& MLS & LS, MS, USLM & Lambert et al. (2007) \\
$\mathrm{HNO}_{3}$ & MLS & UTLS & Santee et al. (2007) \\
$\mathrm{N}_{2} \mathrm{O}$ & ACE-FTS & LS, MS & Strong et al. (2008) \\
& MLS & LS, MS & Lambert et al. (2007) \\
$\mathrm{O}_{3}$ & ACE-FTS & UTLS, LS & Dupuy et al. (2009); Hegglin et al. (2008) \\
& MLS & UTLS, LS & Froidevaux et al. (2008); Livesey et al. (2008) \\
\hline
\end{tabular}

MLS instrument on the EOS Aura satellite is given by Waters et al. (2006). Aura is in a $98^{\circ}$ inclination orbit, and the Aura MLS fields-of-view point in the direction of orbital motion and vertically scan the limb in the orbit plane, leading to data coverage from $82^{\circ} \mathrm{S}$ to $82^{\circ} \mathrm{N}$ latitude on every orbit. Vertical profiles are measured every $165 \mathrm{~km}$ along the suborbital track and have a horizontal resolution of $\sim 200-300 \mathrm{~km}$ along-track and $\sim 3-9 \mathrm{~km}$ across-track. Vertical resolution of the Aura MLS data is typically $\sim 3-4 \mathrm{~km}$ in the upper troposphere through the middle stratosphere, degrading to 5-8 km in the upper stratosphere and mesosphere, depending on the product (Livesey et al., 2007). We use version 2.2 (v2.2) $\mathrm{H}_{2} \mathrm{O}, \mathrm{N}_{2} \mathrm{O}, \mathrm{CO}, \mathrm{HNO}_{3}$, and $\mathrm{O}_{3}$ from MLS to detail transport processes from the upper troposphere into the lower mesosphere, and MLS temperatures (validated by Schwartz et al., 2008) for radiation calculations. For maps, MLS data are gridded using weighted averages of each day's data in the region around each gridpoint.

SCISAT-1, otherwise known as ACE (Bernath et al., 2005), was launched in August 2003. The primary instrument is the ACE-FTS, a Fourier transform spectrometer featuring high resolution $\left(0.02 \mathrm{~cm}^{-1}\right.$, corresponding to a $\pm 25 \mathrm{~cm}$ maximum optical path difference) and broad spectral coverage in the infrared $\left(750-4400 \mathrm{~cm}^{-1}\right)$. ACE-FTS works primarily in the solar occultation mode, collecting atmospheric limb measurements using the sun as a radiation source. Version 2.2 of the ACE-FTS retrievals (Boone et al., 2005 ) is used here, except for $\mathrm{O}_{3}$, for which the ACE-FTS product known as "version 2.2 ozone update" is used (Dupuy et al., 2009). ACE-FTS vertical resolution is $\sim 3-4 \mathrm{~km}$. Latitudes of measurements vary over an annual cycle with coverage as high as $\pm 85^{\circ}$ and an emphasis on the polar regions in winter and spring.

\subsection{Models and calculations}

SLIMCAT 3-D CTM (Chipperfield et al., 1996; Chipperfield, 1999) simulations are compared with ACE-FTS and MLS observations. Feng et al. (2005) show that the updated
SLIMCAT model, with a hybrid $\sigma-\theta$ vertical coordinate and a more sophisticated radiation scheme, produces more realistic representations of tracer transport than the previous scheme, which tended to underestimate descent. The simulation analyzed here has $2.8^{\circ} \times 2.8^{\circ}$ horizontal resolution, with 50 levels from the surface to $3000 \mathrm{~K}(\sim 60 \mathrm{~km})$, using purely isentropic surfaces above $350 \mathrm{~K}$. For each MLS measurement an equivalent sample, interpolated to the same location, is taken from the model at the nearest available time (always within $15 \mathrm{~min}$ ). Winds and temperatures sampled at T42 resolution from the operational ECMWF analyses (e.g., Simmons et al., 2005) are used to drive the SLIMCAT model. Because ECMWF switched from the T512, 60-level model to the T799, 91-level model with top at $0.01 \mathrm{hPa}$ on 1 February 2006 , the simulations during the first approximately $2 / 3$ of the period shown here are driven with winds and temperatures from a model with a top near $60 \mathrm{~km}$, at some times and places lower than the model top at $3000 \mathrm{~K}$.

The SLIMCAT model run used in this paper was initialized at 00:00 UTC on 15 November 2005 using fields from a run started at Aura launch, but replacing $\mathrm{O}_{3}, \mathrm{H}_{2} \mathrm{O}, \mathrm{HCl}$, $\mathrm{HNO}_{3}$ and $\mathrm{CO}$ in the long-term run with values derived from MLS v2.2 data at the new initialization time. $\mathrm{O}_{3}, \mathrm{H}_{2} \mathrm{O}, \mathrm{HCl}$, $\mathrm{HNO}_{3}$ and $\mathrm{N}_{2} \mathrm{O}$ were replaced by v2.2 MLS data gridded as described above for the maps and interpolated to the model grid. Because of vertical oscillations in MLS CO data (albeit much less severe in v2.2 than in v1.5, Pumphrey et al., 2007), these data were smoothed in the vertical and then zonally averaged equatorward of $45^{\circ}$ and in EqL poleward of $45^{\circ}$ for the initialization. More details of the model configuration are given by Santee et al. (2008).

Results from the Global Modeling Initiative (GMI) "Aura4" run (Strahan et al., 2007, and references therein) were examined to help evaluate differences in transport calculations related to the assimilated meteorological fields used to drive them. The GMI Aura4 run was driven with GEOS-4 (Bloom et al., 2005) fields. 


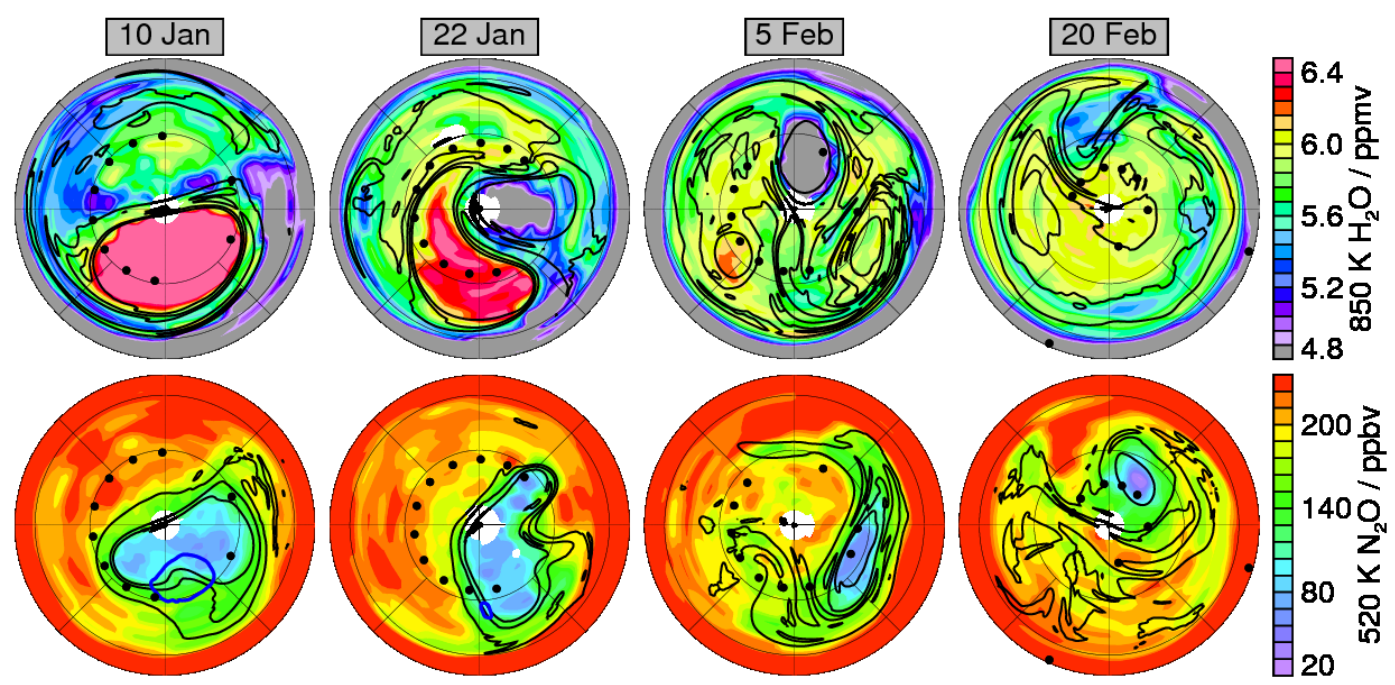

Fig. 1. Maps of MLS long-lived trace gases in the middle $(850 \mathrm{~K}, \sim 10 \mathrm{hPa}, \sim 30 \mathrm{~km})$ and lower $(520 \mathrm{~K}, \sim 50 \mathrm{hPa}, \sim 19 \mathrm{~km}) \mathrm{stratosphere}$ before (10 January), during (22 January, 5 February) and after $\left(20\right.$ February) the $2006 \mathrm{SSW} . \mathrm{H}_{2} \mathrm{O}$ is shown at $850 \mathrm{~K}$ and $\mathrm{N}_{2} \mathrm{O}$ at $520 \mathrm{~K}$. Red/pink colors indicate high values, blue/purple colors low values. Overlaid black contours are sPV in the vicinity of the vortex edge; overlaid blue contour at $520 \mathrm{~K}$ is a temperature of $195 \mathrm{~K}$, near the PSC formation threshold (only present on 10 and 22 January). Black dots show ACE measurement locations on each day. Projection is orthographic, with $0^{\circ}$ longitude at the bottom and $90^{\circ} \mathrm{E}$ to the right; domain is 0 to $90^{\circ} \mathrm{N}$.

Reverse trajectory (RT) calculations (e.g., Sutton et al., 1994; Manney et al., 1998) are used to examine transport in the UTLS. These calculations are done on isentropic surfaces using GEOS-5 horizontal winds, and are initialized with MLS data eight days prior to the date of interest. They provide an estimate of the fine-scale structure predicted based on transport of the coarse-resolution MLS fields.

Radiation calculations have been done to assess vertical motion for interpretation of the MLS measurements. A longwave band model adapted from the Community Climate Model, Version 2 (CCM2) radiation code (Briegleb, 1992a) is used (the SLIMCAT model also uses a version of this code). This is a $100 \mathrm{~cm}^{-1}$ band model that considers infrared opacity by $\mathrm{H}_{2} \mathrm{O}, \mathrm{CO}_{2}, \mathrm{O}_{3}, \mathrm{CH}_{4}, \mathrm{~N}_{2} \mathrm{O}, \mathrm{CFC}-11$, and CFC- 12 . The shortwave radiative heating is calculated using the $\delta$ Eddington approximation with 18 spectral bands (Briegleb, 1992b). The CCM2 radiation code has been validated against line-by-line longwave calculations and in comparisons with Earth Radiation Budget Experiment longwave fluxes and shortwave albedos (Briegleb, 1992a,b). $\mathrm{H}_{2} \mathrm{O}$ and $\mathrm{O}_{3}$ derived from MLS profiles are used for all calculations; other trace gases, tropospheric temperatures, and tropospheric clouds are based on a combined UARS climatology appropriate for high-latitude winter (Minschwaner et al., 1998). To focus on the sensitivity of diabatic heating to temperature differences, all other inputs are fixed for a given day, and diabatic heating rates (averaged over a day) are calculated from time series of zonal mean profiles of 12:00-UTC temperature from MLS (daily average centered around 12:00 UT), GEOS-4, GEOS-5 and ECMWF. Manney et al. (2008b) used similar calculations to show that GEOS-5 and ECMWF both misrepresented the diabatic cooling in the USLM on selected days after the SSW, which may be expected to lead to biases in transport model simulations driven with fields from these analyses.

\section{SSW and transport overview: the middle and lower stratosphere}

Examination of MLS, ACE-FTS, and SLIMCAT-modeled trace-gas evolution in the middle and lower stratosphere allows us to verify the general features of transport that are expected from previous model studies and observations during minor SSWs, and to extend those results to provide a detailed description of transport and our ability to model it in this region. Figure 1 shows maps of MLS long-lived tracers in the middle $\left(850 \mathrm{~K}, \sim 10 \mathrm{hPa}, \mathrm{H}_{2} \mathrm{O}\right)$ and lower $(520 \mathrm{~K}, \sim 50 \mathrm{hPa}$, $\mathrm{N}_{2} \mathrm{O}$ ) stratosphere, with overlaid GEOS-5 scaled PV (sPV) (e.g., Manney et al., 1994b) contours demarking the strong gradients in the vortex edge region. Other trace gases measured by MLS show a consistent picture at each level. The MLS species' gradients are closely correlated with the overlaid SPV fields, indicating a consistent representation of the vortex in both the MLS data and the GEOS-5 sPV. Scatter plots of MLS tracers versus PV (not shown) indicate compact, albeit nonlinear, relationships, confirming this result.

In early winter, the high values of MLS $\mathrm{H}_{2} \mathrm{O}$ in the middle stratosphere indicate confined descent within the vortex before the SSW (10 January). A strong Aleutian anticyclone formed during a strong minor warming preceding the major 

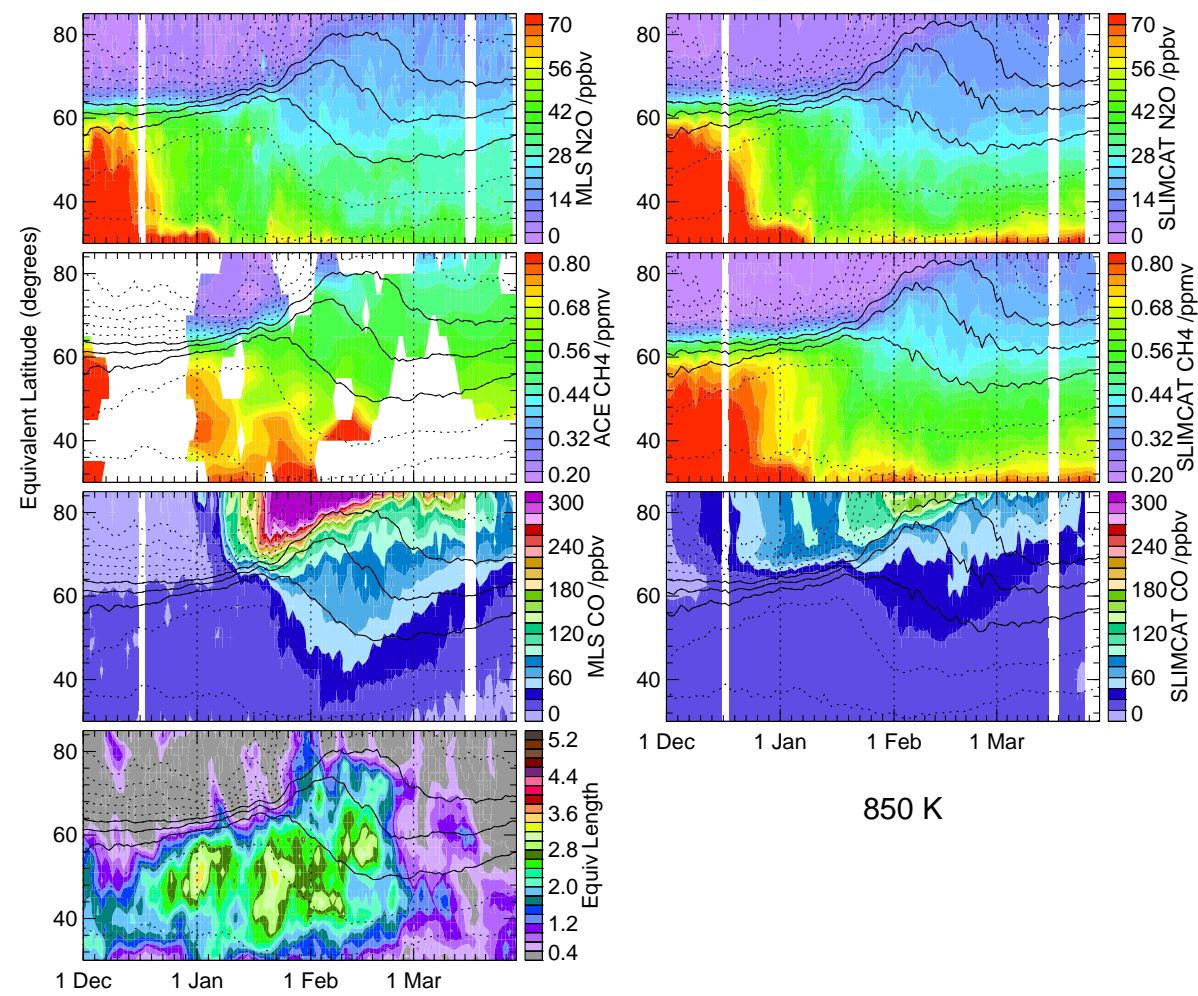

$850 \mathrm{~K}$

Fig. 2. Equivalent latitude (EqL)/Time plots of observed (left) and SLIMCAT modeled (right) $\mathrm{N}_{2} \mathrm{O}$ (MLS, top), $\mathrm{CH}_{4}$ (ACE-FTS, center) and CO (MLS, bottom) during the 2005-2006 NH winter on the $850 \mathrm{~K}$ isentropic surface. Lower left panel is effective diffusivity (K $\mathrm{K}_{\mathrm{eff}}$ ) expressed as log-normalized equivalent length. Overlays are GEOS-5 (ECMWF) sPV contours on MLS and ACE-FTS (SLIMCAT) plots, with solid contours at values that are typically in the region of strong gradients demarking the vortex edge.

SSW, and was apparent at $850 \mathrm{~K}$ over the dateline on $10 \mathrm{Jan}-$ uary. The low $\mathrm{H}_{2} \mathrm{O}$ values surrounding the core of the anticyclone (along with low sPV), and elevated values within its core, suggest that low latitude air was drawn up between the anticyclone and vortex and subsequently coiled up inside the anticyclone, as is common during SSWs (e.g. O'Neill et al., 1994) (this picture has been confirmed using RT calculations, not shown). According to Coy et al. (2009), the major SSW was generated on about 20 January at $60^{\circ} \mathrm{N}$ by an anticyclonic circulation consisting of PV values normally associated with the tropics (see their Fig. 1). As seen in our Fig. 1, this anticyclonic circulation transports very low $\mathrm{H}_{2} \mathrm{O}$ values towards higher latitudes where they are closely confined with little mixing as long as the anticyclone remains strong. By 22 January, when zonal mean winds had reversed, the vortex had shrunk into a crescent shape and shifted off the pole. Consequently, the anticyclone (containing very low $\mathrm{H}_{2} \mathrm{O}$ values indicative of air drawn up from low latitudes) moved near the pole and by 27 January was centered over it (not shown). Decreasing $\mathrm{H}_{2} \mathrm{O}$ in the vortex and increasing values spreading through mid-latitudes indicate the strong mixing during the SSW. The vortex continued to decay, so that by 5 February, only a small remnant of high $\mathrm{H}_{2} \mathrm{O}$ remained near $300^{\circ} \mathrm{E}$, with a small, but strong, anticyclone $\left(\right.$ low $\left.\mathrm{H}_{2} \mathrm{O}\right)$ centered near the date line. By 20 February, $\mathrm{H}_{2} \mathrm{O}$ gradients were very weak throughout the hemisphere, suggesting complete breakdown of the transport barriers that inhibit mixing. The vortex and tracer gradients remained weak through the rest of the winter.

The lower stratosphere was affected by the SSW somewhat later than higher altitudes. On 10 January, the vortex was relatively large and strong, and shifted towards the Greenwich meridian, with a large region of temperatures below the PSC formation threshold (blue overlay) on the equatorward edge, in a typical lower stratospheric wintertime pattern. Low levels of $\mathrm{N}_{2} \mathrm{O}$ in the vortex are a signature of descent. By 22 January, the vortex was quite distorted, and beginning to shrink, but relatively strong $\mathrm{SPV}$ gradients remained along the vortex edge and $\mathrm{N}_{2} \mathrm{O}$ values remained low within the vortex; only a very small region of PSC temperatures persisted right at the vortex edge. By 5 February, the vortex had shrunk to a narrow crescent near $60^{\circ} \mathrm{N}$, with low $\mathrm{N}_{2} \mathrm{O}$ values limited to a small region in its interior. By 20 February, only a small vortex remnant persisted near $120^{\circ}$ E. This well-defined remnant, with very low $\mathrm{N}_{2} \mathrm{O}$ values, lingered throughout the winter, eventually being encompassed by a larger, but weak, reformed vortex with intermediate $\mathrm{N}_{2} \mathrm{O}$ values (not shown). 


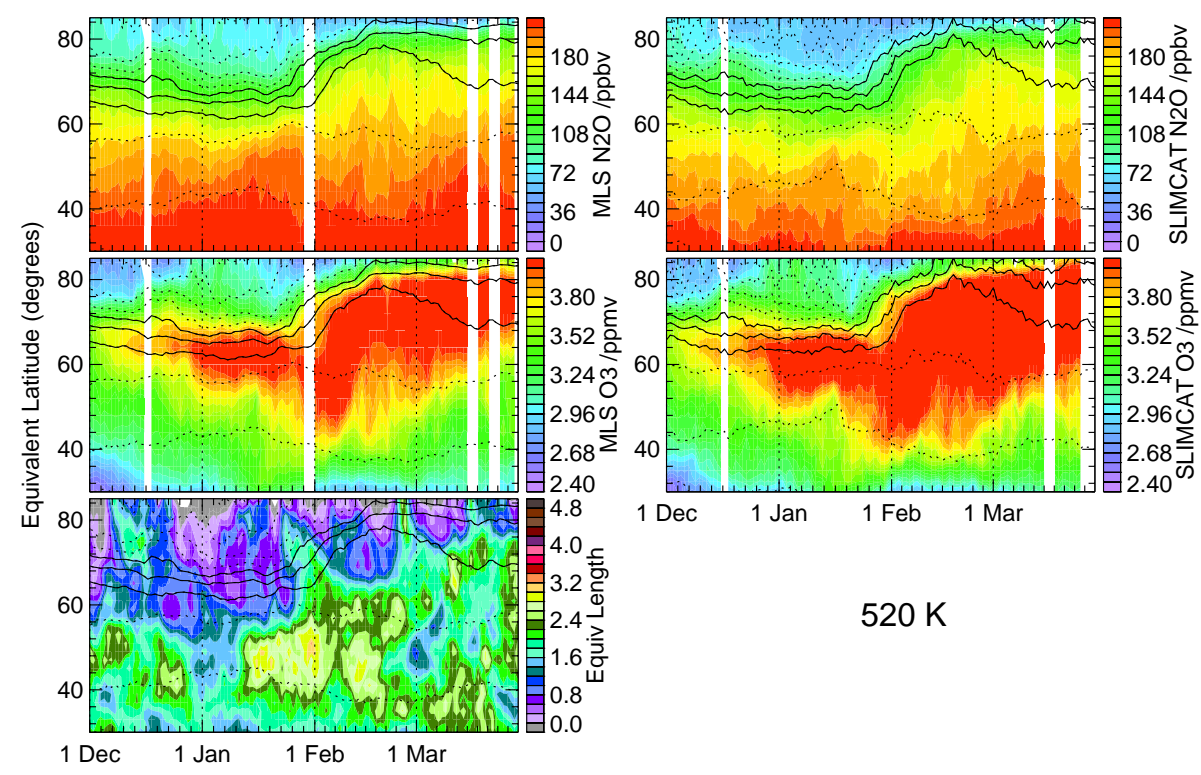

Fig. 3. As in Fig. 2, but showing MLS (left) and SLIMCAT (right) $\mathrm{N}_{2} \mathrm{O}$ and $\mathrm{O}_{3}$ at $520 \mathrm{~K}$.

The MLS trace gas signatures of vortex air (high $\mathrm{H}_{2} \mathrm{O}$, low $\mathrm{N}_{2} \mathrm{O}$ ) show a strong westward tilt with height developing during the SSW: Whereas the vortex at both levels shown in Fig. 1 is centered near $20^{\circ} \mathrm{E}$ on 10 January, by 22 January it is near $45^{\circ} \mathrm{E}\left(0^{\circ} \mathrm{E}\right)$ at $520 \mathrm{~K}(850 \mathrm{~K})$, and by 5 February the main vortex remnant is near $60^{\circ} \mathrm{E}\left(315^{\circ} \mathrm{E}\right)$ at $520 \mathrm{~K}(850 \mathrm{~K})$. Examination of the 3-D structure (not shown) confirms this to be a westward tilt of a contiguous vortex. Similar vortex behavior has been reported in previous studies of SSWs (e.g., Fairlie et al., 1990; Manney et al., 1994a, 1999a, 2005b), and is evidence of upward propagation of wave activity according to linear theory.

Figures 2 and 3 show EqL/time plots of observed and SLIMCAT-modeled trace gases at 850 and $520 \mathrm{~K}$, respectively. $\mathrm{K}_{\text {eff }}$ is also shown to identify regions of mixing and transport barriers. We show MLS $\mathrm{N}_{2} \mathrm{O}$ and CO, and ACEFTS $\mathrm{CH}_{4}$ at $850 \mathrm{~K}$. For MLS and SLIMCAT (which was sampled at MLS observation locations), each EqL/time bin is filled with a number of points comparable to what would result from a zonal mean, typically 10 to 50 points in each EqL bin; in contrast, the sparse ACE sampling results in a typical bin being represented by one to a few data points. Thus, the ACE fields are not only less complete, but noisier and more dependent on the details of the sampling (e.g., Manney et al., 2007). Subject to this constraint, ACE-FTS $\mathrm{N}_{2} \mathrm{O}$ and $\mathrm{CO}$ (not shown) agree well with those from MLS, and $\mathrm{H}_{2} \mathrm{O}$ from both instruments evolves consistently with the fields shown here. $\mathrm{CH}_{4}$, like $\mathrm{N}_{2} \mathrm{O}$, decreases with altitude, and thus low values in the vortex are the signature of confined descent. The $\mathrm{K}_{\text {eff }}$ evolution indicates that the transport barrier almost completely breaks down at $850 \mathrm{~K}$ at the beginning of February, and remains weak and encloses a small area throughout February; sPV gradients strengthen in early
March, and although they remain much weaker than before the SSW, the $\mathrm{K}_{\text {eff }}$ suggests re-establishment of a weak transport barrier near $50^{\circ} \mathrm{EqL}$. Consistent with the evolution of $\mathrm{K}_{\text {eff }}$ and sPV, $\mathrm{N}_{2} \mathrm{O}$ and $\mathrm{CH}_{4}$ show strong gradients across the vortex edge before the warming, with areas of low $\mathrm{N}_{2} \mathrm{O}$ and $\mathrm{CH}_{4}$ spreading out through mid-EqLs during the warming and forming weak, but significant, gradients parallel to those in $\mathrm{K}_{\text {eff }}$ during the weak recovery. High $\mathrm{CO}$ values descending in the vortex did not reach down to $850 \mathrm{~K}$ until early January (see below). During the vortex breakdown, mixing is readily apparent in the high MLS CO values spreading out to $\sim 40^{\circ} \mathrm{EqL}$. A small remnant of vortex air at highest EqLs can be identified throughout the SSW, with more moderate $\mathrm{N}_{2} \mathrm{O}$ and $\mathrm{CH}_{4}$ values at mid-EqLs forming slightly stronger gradients as a transport barrier reforms in late February.

SLIMCAT appears to do a very good job of reproducing the quasi-horizontal transport and mixing associated with the SSW in the middle stratosphere, with only small differences in detail in the time evolution: Slightly lower $\mathrm{N}_{2} \mathrm{O}$ and $\mathrm{CH}_{4}$ in early February, and slightly stronger $\mathrm{N}_{2} \mathrm{O}$ and $\mathrm{CH}_{4}$ gradients as the vortex weakly reforms, suggest the possibility of an underestimate in mixing in SLIMCAT. SLIMCAT vortex CO values, higher than MLS in December, and lower in January, suggest inaccuracies in the diabatic descent (calculated from ECMWF temperatures) used in the model. Since SLIMCAT had apparently not brought down enough CO to this level before the warming to closely match MLS (and ACE-FTS, which agrees well with MLS, not shown), a meaningful assessment of agreement during and after the SSW cannot be made; SLIMCAT does, however, show an increase in values at mid-EqLs at the end of January, with timing similar to that observed. 

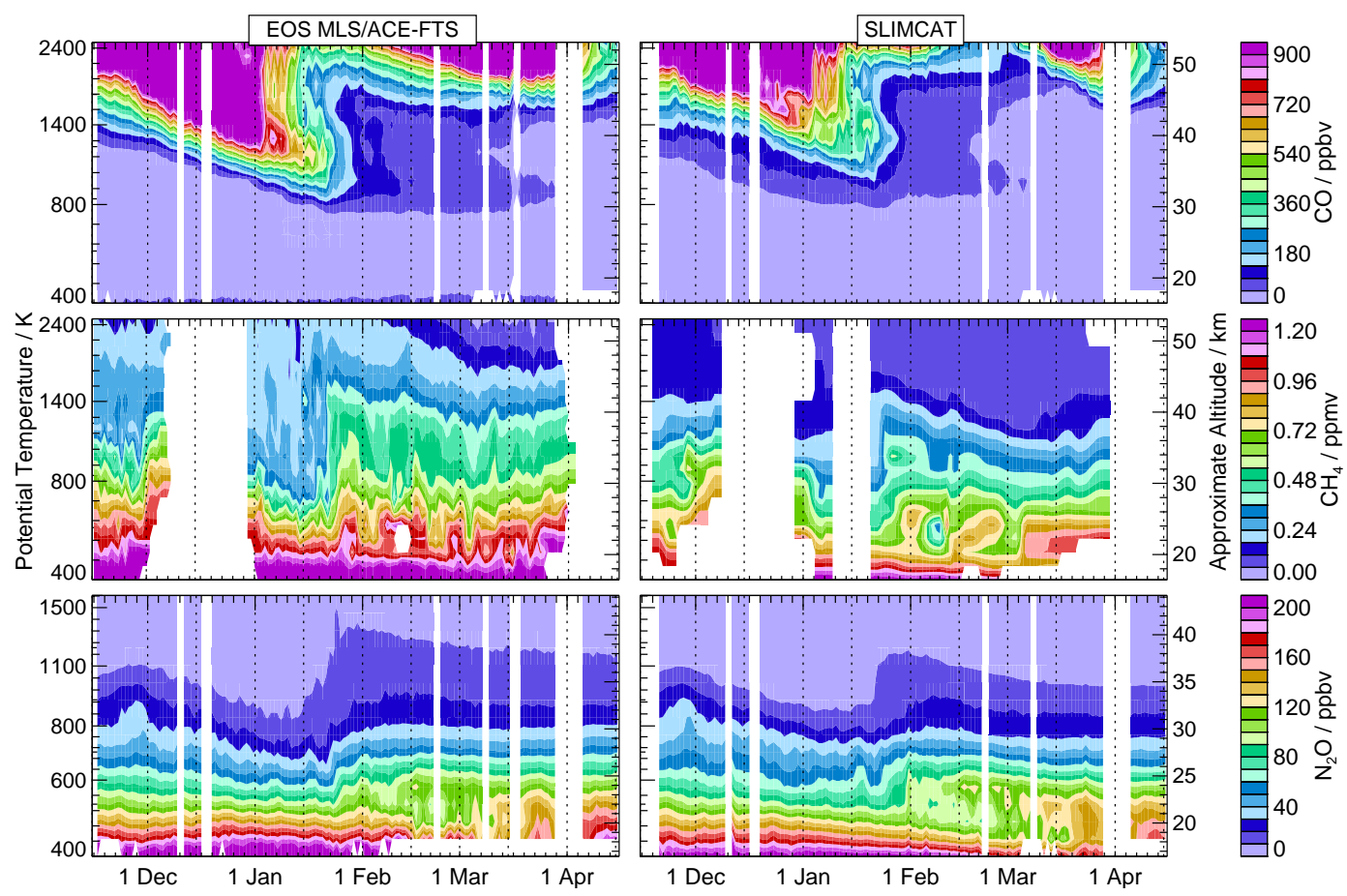

Fig. 4. Vortex averaged (within $1.4 \times 10^{-4} \mathrm{~s}^{-1} \mathrm{sPV}$ contour) (top to bottom) MLS CO, ACE-FTS CH $\mathrm{CH}_{4}$, and MLS $\mathrm{N}_{2} \mathrm{O}$ (left) and SLIMCAT simulations (right). Vertical range is from 400 to $2500 \mathrm{~K}$ (into the lower mesosphere) for $\mathrm{CO}$ and $\mathrm{CH}_{4}$, but 400 to $1600 \mathrm{~K}$ (through the middle stratosphere) for $\mathrm{N}_{2} \mathrm{O}$. SLIMCAT $\mathrm{CH}_{4}$ is sampled near the ACE observation locations for the average shown here.

Figure 3 shows MLS $\mathrm{N}_{2} \mathrm{O}$ and $\mathrm{O}_{3}$ in the lower stratosphere at $520 \mathrm{~K}$. Here, the vortex was relatively strong and cold until late January. The decrease seen in $\mathrm{O}_{3}$ in the vortex core during January has been shown to be inconsistent with transport (note that $\mathrm{N}_{2} \mathrm{O}$ decreases at this time and place, indicating diabatic descent that would increase $\mathrm{O}_{3}$ ) and consistent with chemical loss, with rough estimates using MLS data suggesting $\sim 0.5-0.7$ ppmv chemical loss during January 2006 (Braathen et al., 2006). The vortex breakdown during the SSW began at the end of January, and was more gradual and less complete than that at higher levels, with a region of reduced mixing (seen as lingering low $\mathrm{K}_{\mathrm{eff}}$ values) remaining in the vortex core throughout the winter. This is consistent with the clearly identifiable remnants of vortex (low $\mathrm{N}_{2} \mathrm{O}$ ) air seen in Fig. 1. The observed evolution of $\mathrm{H}_{2} \mathrm{O}$ (MLS and ACE-FTS) and $\mathrm{CH}_{4}$ (ACE-FTS), not shown, is consistent with that of $\mathrm{N}_{2} \mathrm{O}$.

SLIMCAT shows slightly lower $520 \mathrm{~K} \mathrm{~N}_{2} \mathrm{O}$ (and higher $\mathrm{H}_{2} \mathrm{O}$, not shown) inside the vortex and its remnants throughout the period shown, suggesting the possibility that lower stratospheric descent in SLIMCAT may be slightly too strong. In early February in the region outside the vortex remnant, air with low $\mathrm{N}_{2} \mathrm{O}$ values spreads to lower EqLs in SLIMCAT than in MLS, suggesting more mixing into midlatitudes from the outer part of the vortex. Since stronger mixing would tend to increase vortex $\mathrm{N}_{2} \mathrm{O}$, the presence of lower values in SLIMCAT than in MLS reinforces the evidence that descent in the vortex in SLIMCAT is too strong.
The decrease in SLIMCAT $\mathrm{O}_{3}$ in January to early February is very similar in magnitude and evolution to that in MLS. This is consistent with the results of Santee et al. (2008), who show, however, that the good agreement in polar $\mathrm{O}_{3}$ evolution may result from a fortuitous combination of conditions, since SLIMCAT chlorine activation and partitioning show significant deficiencies in the model formulation used here.

The overview given above provides observational confirmation of aspects of stratospheric transport during strong SSWs previously documented in modeling studies, and details other aspects that are consistent with expectations from dynamical studies. General features are common to most major SSWs: The vortex and trace gases confined within it tilt westward with height. Material is drawn up around the vortex and coils up in the high-latitude anticyclone that forms as the vortex breaks down; tongues of material are also drawn off vortex. The transport barrier breaks down earlier and more completely in the middle than in the lower stratosphere, consistent with the dynamical evolution of the vortex shown in previous studies (e.g., Fairlie et al., 1990; Manney et al., 2005a). Features that are specific to the 2006 SSW include the complete disappearance of a vortex transport barrier and dispersal of vortex air resulting from the unusual strength of this SSW, and the slow and weak reformation of the vortex transport barrier and re-establishment of horizontal trace gas gradients that reflect the prolonged nature of the 2006 SSW. 


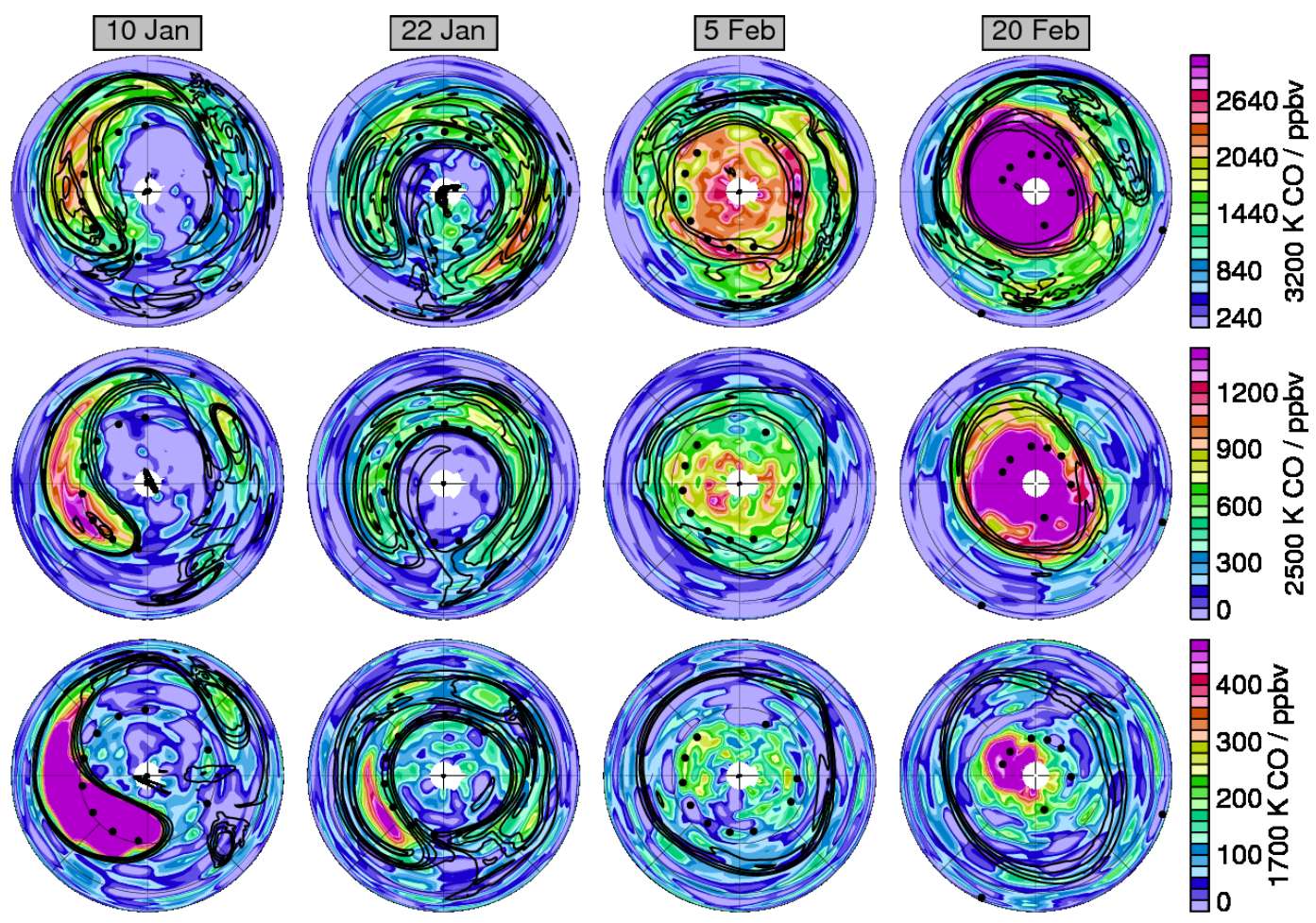

Fig. 5. Maps of MLS CO (ppbv) in the USLM before, during and after the 2006 SSW. Layout and overlays are as in Fig. 1.

Figure 4 shows the evolution of vortex-averaged trace gases in the lower stratosphere through the lower mesosphere, placing the middle and lower stratospheric evolution discussed above in the context of transport in the entire middle atmosphere. For $\mathrm{CH}_{4}$, the analyzed SLIMCAT fields have been sampled near the ACE measurement locations, and the apparent increase prior to the observing gap in late December is a result of the change in latitude of ACE sampling at that time, as described by Manney et al. (2007). Because SLIMCAT was initialized with $\mathrm{CH}_{4}$ that was inconsistent with that from ACE-FTS, it is appropriate to compare gradients and time evolution, but not quantitative values. The evolution of $\mathrm{N}_{2} \mathrm{O}, \mathrm{CH}_{4}$, and $\mathrm{CO}$ in the lower through the middle stratosphere is consistent with the transport detailed above, showing abrupt increases in $\mathrm{N}_{2} \mathrm{O}$ and $\mathrm{CH}_{4}$ and decreases in $\mathrm{CO}$ in late January coincident with the vortex breakdown in the middle to lower stratosphere. SLIMCAT shows slightly smaller increases when the vortex breaks down (suggesting less mixing in the middle stratosphere), and a slightly stronger downward tilt of the contours indicating more descent. Before the warming, the SLIMCAT simulations suggest slower descent than the satellite data in the middle stratosphere and above, but stronger descent below $600 \mathrm{~K}$ for the same period. While SLIMCAT $\mathrm{CH}_{4}$ values above $\sim 700 \mathrm{~K}$ are initially lower than those for MLS, they do not decrease as rapidly as in the ACE-FTS observations, and SLIMCAT CO values below $\sim 1700 \mathrm{~K}$ do not increase as rapidly as those in MLS. Stronger descent in SLIMCAT than in MLS in the lower stratosphere in a similar simulation was noted by Santee et al. (2008). After the SSW, vortex averaged $\mathrm{N}_{2} \mathrm{O}$ and $\mathrm{CH}_{4}$ in the middle and lower stratosphere remained nearly constant, consistent with the weak recovery at these levels noted above (the apparent increase in $\mathrm{CH}_{4}$ in late March reflects the changing sampling of ACE-FTS). The behavior of CO in the USLM is discussed further in Sect. 4.

The results shown above confirm and extend those of previous studies that examined some aspects of transport during SSWs. Very few previous studies have discussed vortex evolution or, especially, transport at higher levels, so our understanding of transport during SSWs in the upper stratosphere and mesosphere has been very rudimentary. In the following section, we detail that evolution using MLS data and the SLIMCAT simulation.

\section{The upper stratosphere and lower mesosphere}

\subsection{Observed and SLIMCAT-modeled transport}

Figure 5 shows the synoptic evolution of the vortex and MLS $\mathrm{CO}$ during the period in maps at $1700 \mathrm{~K}(\sim 1.5 \mathrm{hPa}$, upper stratosphere), $2500 \mathrm{~K}(\sim 0.3 \mathrm{hPa}$, near stratopause), and $3200 \mathrm{~K}(\sim 0.1 \mathrm{hPa}$, mesosphere). As is typical for early winter (e.g., Allen et al., 1999, 2000), by January high levels of CO had been transported downward from the mesosphere 


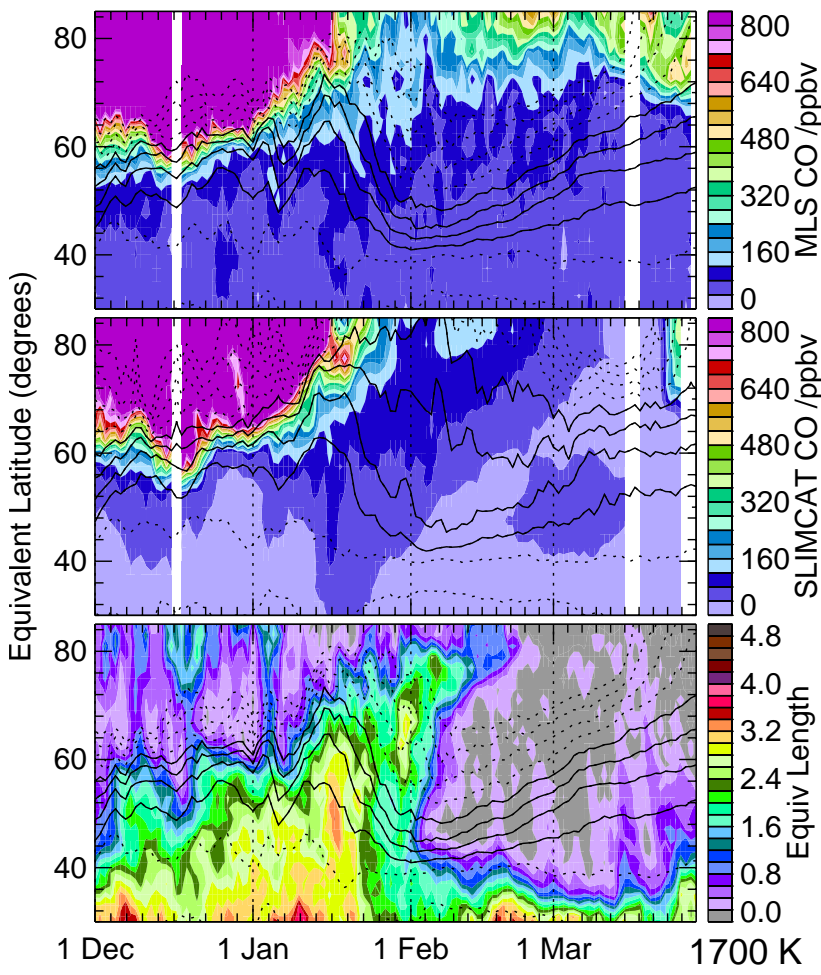

Fig. 6. As in Fig. 2, but for MLS (top) and SLIMCAT (center) CO at $1700 \mathrm{~K}$.

into the upper stratospheric vortex. On 10 January, the USLM vortex was already highly distorted and shifted off the pole, resulting in the zonal mean easterlies previously reported at this time and level (Manney et al., 2008b). The vortex and CO structure suggest substantial mixing of tongues of air with high $\mathrm{CO}$ pulled off the distorted and decaying vortex into midlatitudes. The anticyclone (low $\mathrm{CO}$ at high latitudes) was already over the pole at these levels, and remained so through 22 January. By 5 February, when USLM winds had begun to recover (Manney et al., 2008b), a large, pole-centered vortex had reformed, and $\mathrm{CO}$ was increasing throughout the vortex at $3200 \mathrm{~K}$ and in the vortex core at 2500 and $1700 \mathrm{~K}$. By 20 February, high CO (comparable to values well before the SSW, not shown) filled the lower mesospheric vortex (3200 and $2500 \mathrm{~K}$ ), and maximum values in the upper stratospheric $(1700 \mathrm{~K})$ vortex core were comparable to those before the SSW. The vortex began to weaken at these levels by 15 March, more so at the highest levels, and $\mathrm{CO}$ showed a corresponding large decrease at $3200 \mathrm{~K}$ and slight decrease at $2500 \mathrm{~K}$ (not shown).

Vortex-averaged $\mathrm{CO}$ (Fig. 4), as well as $\mathrm{CH}_{4}$, shows the patterns of vortex descent in the lower mesosphere and upper stratosphere. Figure 6 shows the time evolution of $\mathrm{CO}$ and $\mathrm{K}_{\text {eff }}$ as a function of EqL in the upper stratosphere at $1700 \mathrm{~K}$; ACE-FTS CO (not shown) shows similar values and time evolution to those seen in MLS CO. The evolution of $\mathrm{K}_{\mathrm{eff}}$ indicates a complete breakdown of the vortex transport bar- rier, with high values indicative of strong mixing extending to high EqL after mid-January. A strong transport barrier reforms almost immediately north of $40^{\circ} \mathrm{EqL}$, along with reformation of a strong vortex. As expected from general studies of descent in the vortex (e.g., Fisher et al., 1993; Allen et al., 1999), the signature of strong, relatively monotonic descent is seen before the SSW, until early January. Because $\mathrm{CO}$ values are at very low stratospheric background values ( 12-15 ppbv, e.g., Flocke et al., 1999) outside the vortex (Fig. 6), and very high values have been transported down into the vortex through the middle stratosphere when the SSW starts, the signature of the vortex breakdown is very dramatic in the vortex averages: In early January, $\mathrm{CO}$ values begin to dramatically decrease, most rapidly at levels near and above $\sim 1700 \mathrm{~K}$, with high values lingering until late January in the middle stratosphere (also seen in Fig. 2). As seen in Fig. 6, very low $\mathrm{CO}$ values extend to high $\mathrm{EqL}$ at this time, consistent with the strong, pervasive mixing indicated by the $\mathrm{K}_{\mathrm{eff}}$ evolution. After the SSW, starting in early February when the USLM vortex is reforming and becoming very strong (e.g., Manney et al., 2008b, also see Fig. 5 and overlaid sPV contours in Fig. 6), high MLS CO again descends from the mesosphere, echoing the descent seen in fall/early winter; at $1700 \mathrm{~K}$, the signature of this is an increase in $\mathrm{CO}$ in the vortex core starting in early February, and spreading throughout the vortex by the end of March. A similar signature is seen in ACE-FTS vortex-averaged $\mathrm{CH}_{4}$ (until early March, when sampling effects become significant). The enhanced vortex descent after the warming is consistent with results shown by Randall et al. (2006), Manney et al. (2008a) and Jin et al. (2009).

In the USLM, the SLIMCAT fields show significant discrepancies compared to the satellite observations: Before the SSW, the high vortex CO did not descend as far, suggesting that diabatic descent in the model was too weak at these levels. While the signature of vortex breakdown during the major SSW is generally captured well, the abrupt decrease in $\mathrm{CO}$ is slightly later above $\sim 1700 \mathrm{~K}$, and elevated values linger into February at the highest levels shown in Fig. 4. Figure 6 shows $C O$ values above $\sim 500$ ppbv lingering a few days longer in SLIMCAT than in MLS at high EqL in late January. These patterns suggest some deficiencies in mixing in the model. The largest discrepancy, however, is the failure of the model to produce high CO descending into the vortex immediately after the warming; the signature of this descent does not begin until March (with high vortex CO descending to $1700 \mathrm{~K}$ only at the end of March), and then appears to be too rapid (Fig. 4). This points to significant biases in the diabatic descent in SLIMCAT during the recovery from the SSW. The ECMWF sPV contours overlaid on the SLIMCAT plots in Fig. 6 show substantial differences from those from GEOS-5 on the MLS plots, with a weaker and later vortex reformation after the SSW. These differences are consistent with those noted by Manney et al. (2008b), and related to the biases in the analyzed temperatures and winds 


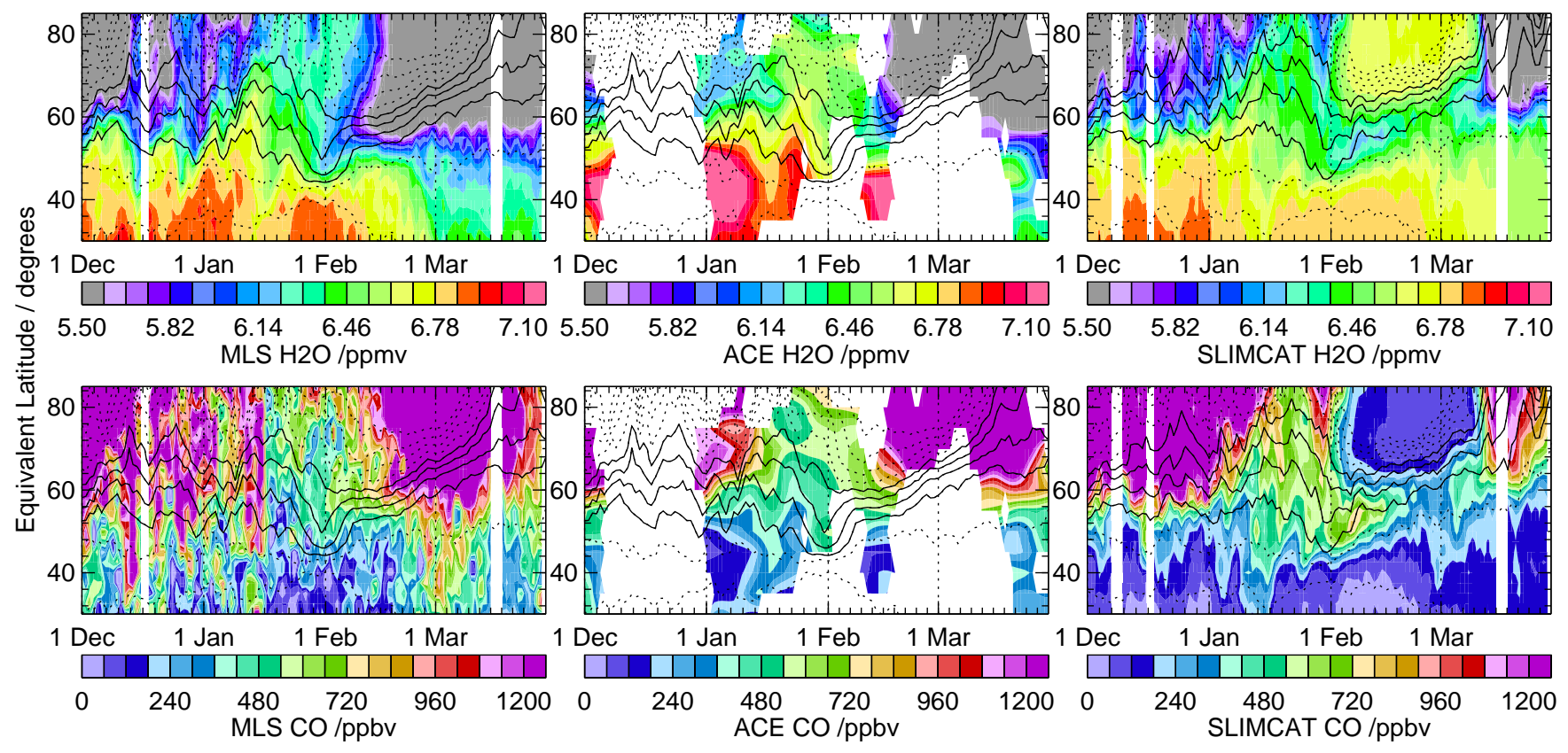

Fig. 7. As in Fig. 2, but for (left to right) MLS, ACE-FTS and SLIMCAT $\mathrm{H}_{2} \mathrm{O}$ (top) and $\mathrm{CO}$ (bottom) on the $2500 \mathrm{~K}$ isentropic surface; $\mathrm{K}_{\text {eff }}$ is not shown/calculated at $2500 \mathrm{~K}$.

from both GEOS-5 and ECMWF. The analyses' temperature biases are expected to strongly influence calculated diabatic descent rates, as discussed in Sect. 4.2.

Figure 7 shows MLS, ACE-FTS, and SLIMCAT $\mathrm{H}_{2} \mathrm{O}$ and $\mathrm{CO}$ at $2500 \mathrm{~K}$, near or just above the stratopause. Although MLS data (especially CO) are noisy at this level, the agreement in values and time evolution between MLS and ACEFTS is good, confirming that both datasets provide an unbiased representation of these fields. The patterns of CO time evolution are similar to those at $1700 \mathrm{~K}$ (Fig. 6), but after the SSW high $\mathrm{CO}$ (and, since $\mathrm{H}_{2} \mathrm{O}$ decreases with height above the middle to upper stratosphere, low $\mathrm{H}_{2} \mathrm{O}$ ) completely fills the vortex by mid-February. The patterns in SLIMCAT, however, emphasize the model's increasing inability to capture the transport at higher altitudes after the warming: SLIMCAT shows a period with high $\mathrm{H}_{2} \mathrm{O}$ and low $\mathrm{CO}$ in the vortex after the SSW, prior to the descent in mid-March of high $\mathrm{CO}$ and low $\mathrm{H}_{2} \mathrm{O}$. The period with these dramatically different values in SLIMCAT immediately follows the switch to driving fields with a higher model top (Sect. 2.3), and thus may be related not only to deficiencies in the contemporaneous transport, but also to vertical transport of values from regions at the top of the ECMWF analyses that had an even poorer representation of earlier transport.

\subsection{USLM descent}

The dramatic deficiencies in SLIMCAT in the USLM after $\sim 5$ February suggest either diabatic ascent in the model, or the possibility of very inappropriate boundary conditions (the model top is at $3000 \mathrm{~K}$ ). However, the eventual appearance of a signature of descent by 15 March in SLIMCAT, and the consistency in the anticorrelation between $\mathrm{H}_{2} \mathrm{O}$ and $\mathrm{CO}$ (e.g., Fig. 7), suggest that inaccurate diabatic descent is likely the primary cause of the failure. Figure 8 shows timeseries of $70^{\circ} \mathrm{N}$ radiative heating rates calculated using MLS and ECMWF temperatures during the 2005-2006 Arctic winter. Modest differences are seen before the SSW, with ECMWF having strongest descent at slightly higher altitudes (near $0.1 \mathrm{hPa}$ ), and slightly weaker descent near and below $1 \mathrm{hPa}$, consistent with the SLIMCAT simulations showing less $\mathrm{CO}$ descending through the upper stratosphere in early winter. The most dramatic differences, however, are after the SSW, in February and March. In February, the ECMWF calculation shows dramatically less descent between $\sim 0.3$ and $0.01 \mathrm{hPa}$, consistent with the biases in ECMWF temperatures during that period noted by Manney et al. (2008b). The duration of the period of zero descent to weak ascent between 0.04 and $0.01 \mathrm{hPa}$ in late January is longer in ECMWF- than MLS-derived profiles, and centered at slightly higher altitude. In late March, MLS-based descent rates decrease, becoming considerably less than those from ECMWF. These results are qualitatively consistent with the signatures in SLIMCAT CO and $\mathrm{H}_{2} \mathrm{O}$ in the USLM suggesting too weak descent (or even ascent) in February, changing to too strong descent in March. 


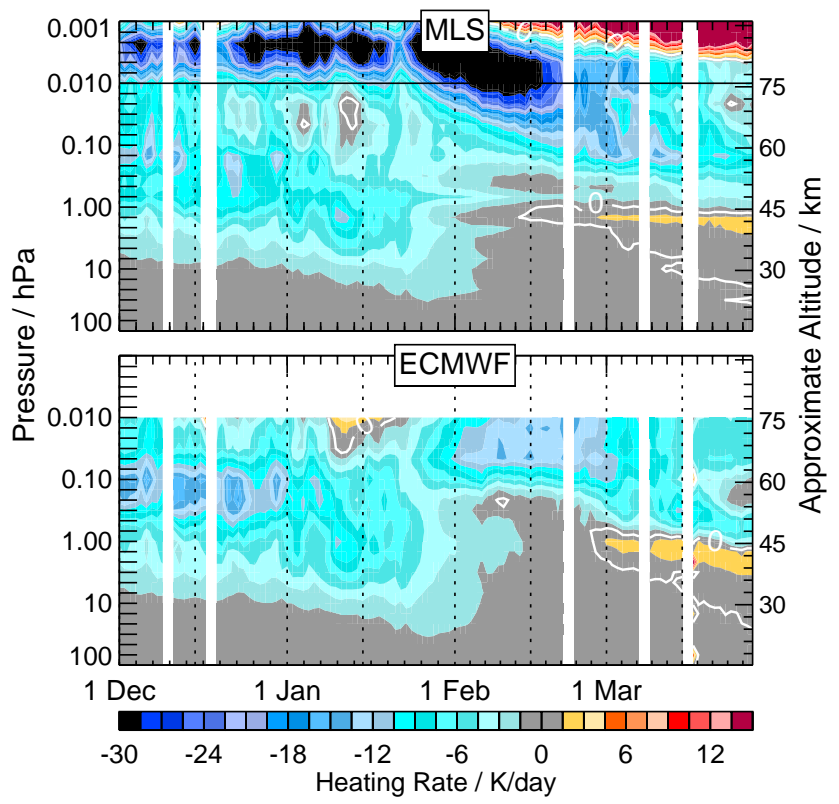

Fig. 8. $70^{\circ} \mathrm{N}$ zonal mean radiative heating (negative values, blue/green colors, indicate diabatic descent; positive values, orange/red colors, indicate ascent) rates calculated from MLS (top) and ECMWF (bottom) temperatures (see text for details).

Manney et al. (2008b) showed that GEOS-5 analyses' temperatures were biased such that radiative cooling derived from them was too strong above $\sim 0.4 \mathrm{hPa}(\sim 1800 \mathrm{~K}$ in the very cold polar regions in mid-February 2006), and too weak (near-zero descent or ascent) near $1 \mathrm{hPa}(\sim 1500 \mathrm{~K}$ at the same time); GEOS-4 temperature structure was similar to that in GEOS-5 (Manney et al., 2008a), thus similar patterns of radiative heating would be expected. Comparison of the time evolution of ACE-FTS, SLIMCAT, and GMI Aura4 (driven by GEOS-4 fields) $\mathrm{CH}_{4}$ at 1700 and $2500 \mathrm{~K}$ and in vortex averages (not shown) indicates that enhanced descent (decreasing $\mathrm{CH}_{4}$ ) in the USLM begins earlier and is more rapid in February in the GMI Aura4 simulation than that indicated by the ACE-FTS data, consistent with the patterns of biases in radiative heating. Examination of GEOS-5 assimilated $\mathrm{H}_{2} \mathrm{O}$ (not shown) indicates a similar bias in GEOS-5 transport with more rapid than expected descent in the 1700 to $2500 \mathrm{~K}$ region in early February.

The results above offer convincing evidence that the deficiencies in the SLIMCAT simulation in the USLM arise primarily from inaccurate temperatures and hence diabatic descent rates after the SSW. The choice of assimilated meteorological fields used to drive transport models is critical to reproducing observed transport. The MLS and ACE-FTS fields shown here provide the first globally distributed daily long-lived trace gas data to thoroughly test the performance of assimilated winds in transport calculations, especially in the USLM and for extreme events, such as this SSW, that severely challenge the abilities of the assimilation systems and underlying GCMs.

\section{The upper troposphere/lower stratosphere}

The MLS (and other Aura instruments, e.g., Olsen et al., 2008) and ACE-FTS (e.g., Hegglin et al., 2008, 2009) datasets also offer the first extensive fields in the upper troposphere and lowermost stratosphere (that portion of the stratosphere below $380 \mathrm{~K}$ where isentropes intersect the tropopause, thus lying partly in the troposphere and partly in the stratosphere, Hoskins, 1991; Holton et al., 1995), allowing comprehensive study of UTLS trace gas fields suitable for detailed examination of transport. UTLS dynamics are closely involved in the occurrence and evolution of SSWs. Coy et al. (2009) showed evidence suggesting that propagation of waves originating from a localized upper tropospheric ridge in mid-January was responsible for triggering the 2006 SSW. Keil et al. (2007) showed an episode of extremely low total column $\mathrm{O}_{3}$ over the $\mathrm{UK}$ at this time, resulting from lofting and anomalous poleward transport associated with the originating region of the SSW in the UTLS. The episodes of upper tropospheric ridging, both that implicated in triggering the SSW and later episodes (e.g., Olsen et al., 2008; Coy et al., 2009), are associated with wave propagation that influences the stratospheric/mesospheric flow and hence transport throughout the middle atmosphere.

Several trace gases measured by MLS are useful in the UTLS; in particular, the morphology and evolution of $\mathrm{O}_{3}$ and $\mathrm{HNO}_{3}$ are well-represented (albeit with some biases) in this region (Livesey et al., 2008; Santee et al., 2007, 2009). Figure 9 shows maps at 380 and $350 \mathrm{~K}$ from MLS, SLIMCAT, and RT calculations (Sect. 2.3) on 17-19 January, during the development of the ridge thought to have triggered the SSW. $\mathrm{O}_{3}$ is shown at $350 \mathrm{~K}$ and $\mathrm{HNO}_{3}$ at $380 \mathrm{~K}$; a consistent picture of the morphology and evolution of the fields is seen between $\mathrm{O}_{3}$ and $\mathrm{HNO}_{3}$ at both levels. The MLS fields reveal the effects of transport associated with three evolving ridges, as described below:

The most intense ridge moved from the mid-Atlantic over the Greenwich meridian during the three days shown, intensifying between 17 and 18 January, and moving slightly equatorward by 19 January. A sequence of upper tropospheric ridges like this is the signature of a Rossby wave train associated with a blocking event, which is often instrumental in forcing SSWs (e.g., Allen et al., 2006, and references therein). Associated with the mid-Atlantic ridge on 17 January is a large tongue of low-latitude, tropospheric air with low $\mathrm{O}_{3}$ and $\mathrm{HNO}_{3}$ drawn up to high latitudes, near $60^{\circ} \mathrm{N}$ (note that the white tropopause contour is drawn into high latitudes and cut off). This is a deep feature, extending down to at least $340 \mathrm{~K}$ (near the lower limit of the MLS data) and up to at least $400 \mathrm{~K}$. It sits directly below the coldest area in the lower stratosphere, consistent with the characteristic dynamical situation during "ozone mini-hole" events (e.g., Allen and Nakamura, 2002), such as that reported by Keil et al. (2007) at this time. 

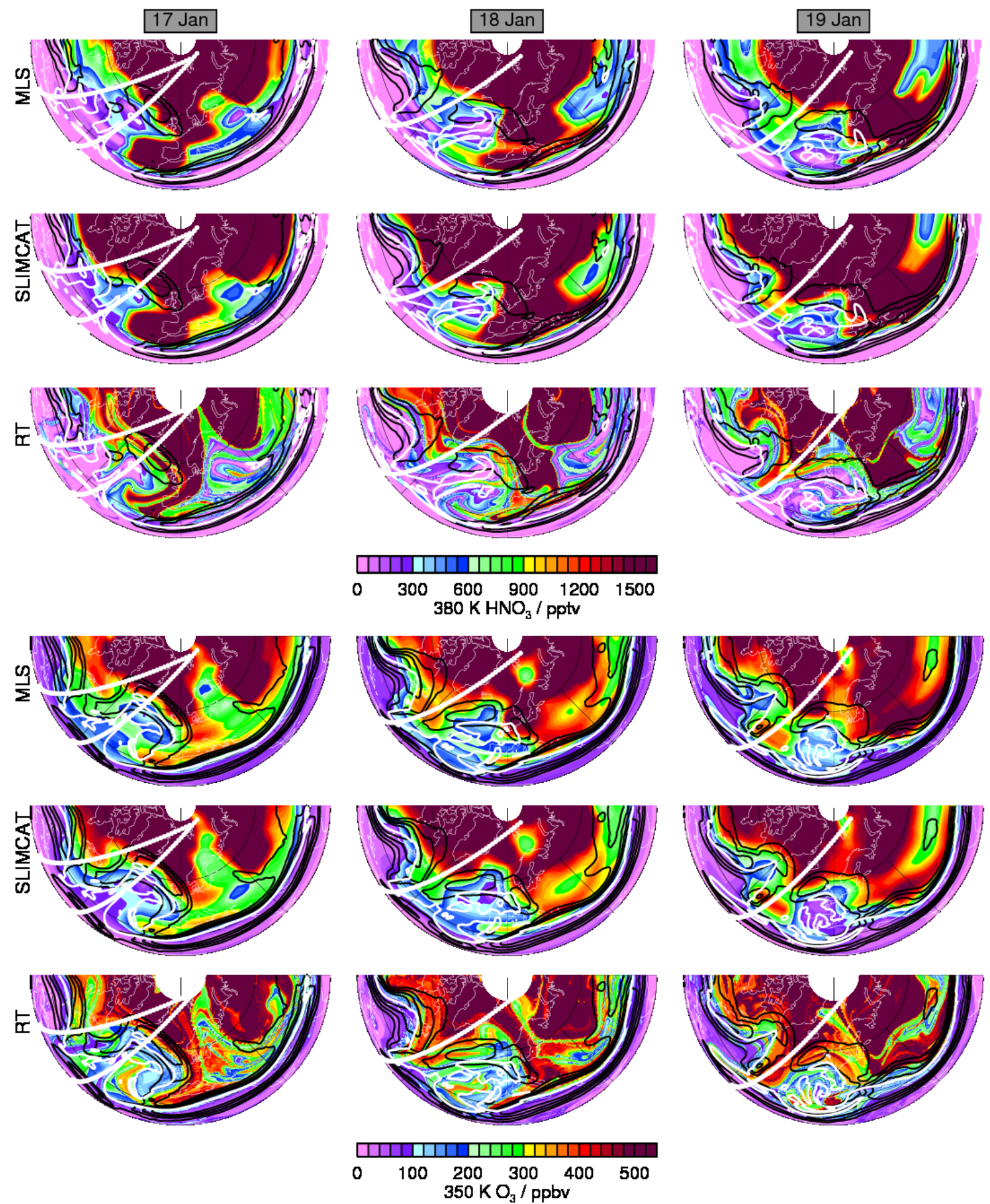

Fig. 9. Maps of (top to bottom for each level/species) MLS, SLIMCAT and RT (see text) $380 \mathrm{~K} \mathrm{HNO}_{3}$ (top set) and $350 \mathrm{~K} \mathrm{O}$ (bottom set) near the beginning of the 2006 SSW. White contour shows the 4.5 "PV Unit" contour that is commonly used as an approximate definition of the extratropical tropopause; black contours show windspeeds of $30,40,50$ and $60 \mathrm{~ms}^{-1} .0$ to $90^{\circ} \mathrm{N}$ and -90 to $90^{\circ} \mathrm{E}$ is shown, with $0^{\circ}$ longitude at the bottom. The white tracks (closely spaced white dots) show the MLS orbit tracks, with a dot at each measurement location, examined in Fig. 10. 

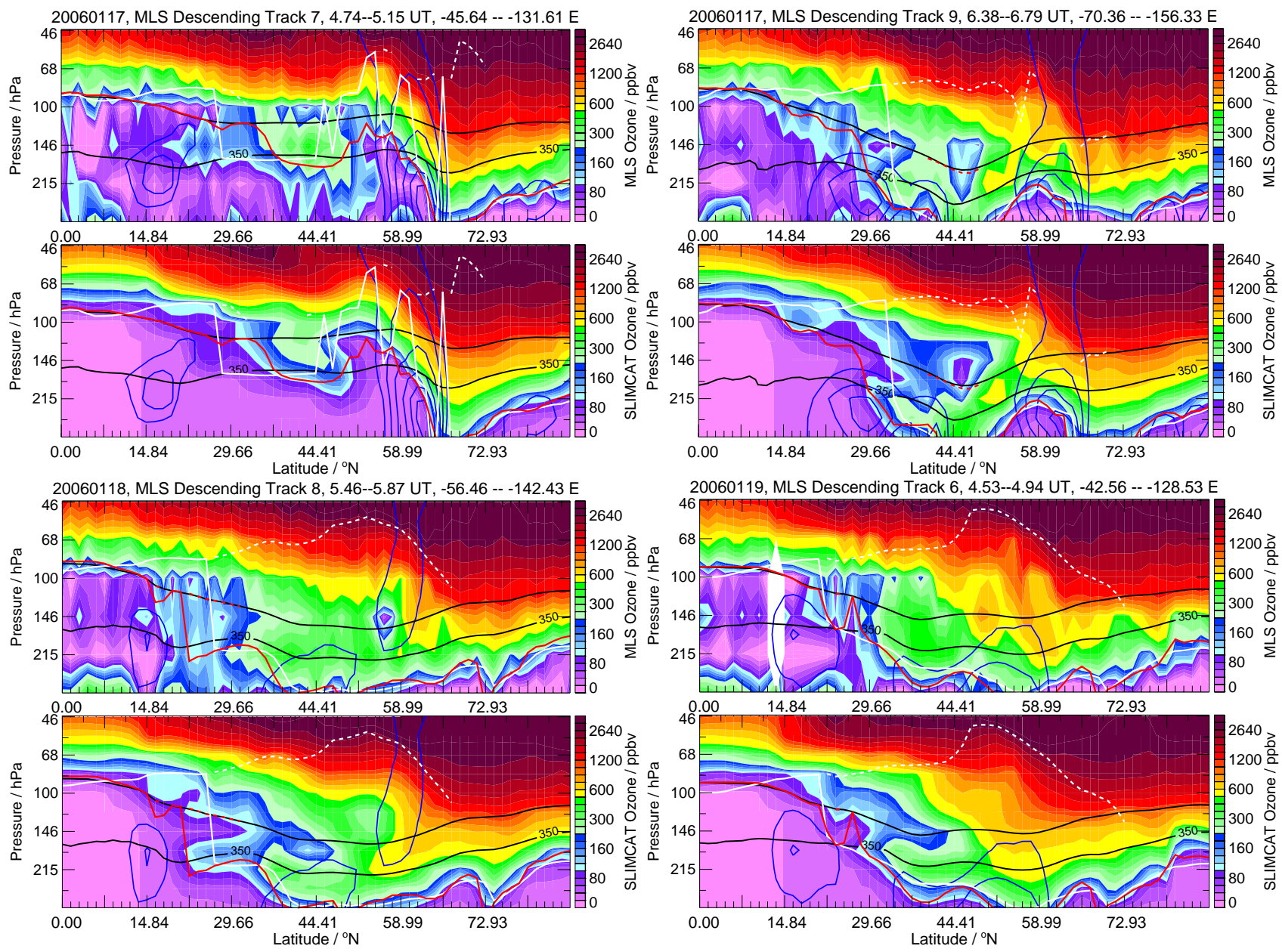

Fig. 10. Plots of MLS and SLIMCAT (top and bottom of each pair, respectively) $\mathrm{O}_{3}$ profiles along orbit tracks on 17-19 January 2006; the orbit tracks shown are overlaid on Fig. 9, with the sections at the top left corresponding to the easternmost track (nearest the Greenwich meridian) on 17 January. Purple colors indicate low $\mathrm{O}_{3}$, red/brown colors high $\mathrm{O}_{3}$. The white line is the thermal (WMO) tropopause from GEOS-5, and the red line the 4.5 PVU dynamical tropopause; dashed lines show secondary tropopauses where they exist. Blue contours are windspeeds from 20 to $60 \mathrm{~m} / \mathrm{s}$ by $10 \mathrm{~ms}^{-1}$. Black contours show the 350 and $380 \mathrm{~K}$ isentropes.

At $380 \mathrm{~K}$, low $\mathrm{O}_{3}$ and $\mathrm{HNO}_{3}$ were transported to high latitudes in conjunction with another strong ridge near $45^{\circ} \mathrm{E}$ on 17 January, which moved slightly eastward and weakened by 19 January, tilting westward with latitude. This ridge was shallower in the vertical and already weakening, thus $350 \mathrm{~K}$ fields show low (but not tropospheric) $\mathrm{O}_{3}$ being drawn into high latitudes on 17 January, but little poleward transport after that. A third ridge, and accompanying transport of tropospheric air to high latitudes, formed near $270^{\circ} \mathrm{E}$ on $17 \mathrm{Jan}-$ uary and subsequently deepened and moved eastward to near $315^{\circ} \mathrm{E}$ by 19 January. The MLS, SLIMCAT, and RT fields all represent this evolution very similarly. This close agreement demonstrates not only the quality of the MLS data for examining the patterns of UTLS transport, but also argues for high quality in the UTLS of winds from both ECMWF and GEOS-5 (the former driving SLIMCAT, the latter, the
RT calculations); these assimilation systems are well constrained by data in this region. The RT fields show finescale structure that is not expected to be captured at the resolution of the MLS and SLIMCAT fields. The details of this fine-scale structure are difficult to verify in the absence of high-resolution measurements; however, previous studies have verified similar structure in RT calculations during periods with aircraft measurements (e.g., Hegglin et al., 2004). A few ACE-FTS profiles (near $60^{\circ} \mathrm{N}$ on these days) were taken in the region of the fine structure, including several along the filament of high $\mathrm{HNO}_{3}$ seen at $380 \mathrm{~K}$ on 17 and 18 January (paralleling the southern edge of the high $\mathrm{HNO}_{3}$ region). Examination of these profiles does suggest some fine structure in the vertical that is consistent between several species and similar to that in profile RT calculations at these locations; however, the quality and resolution of individual ACE-FTS 

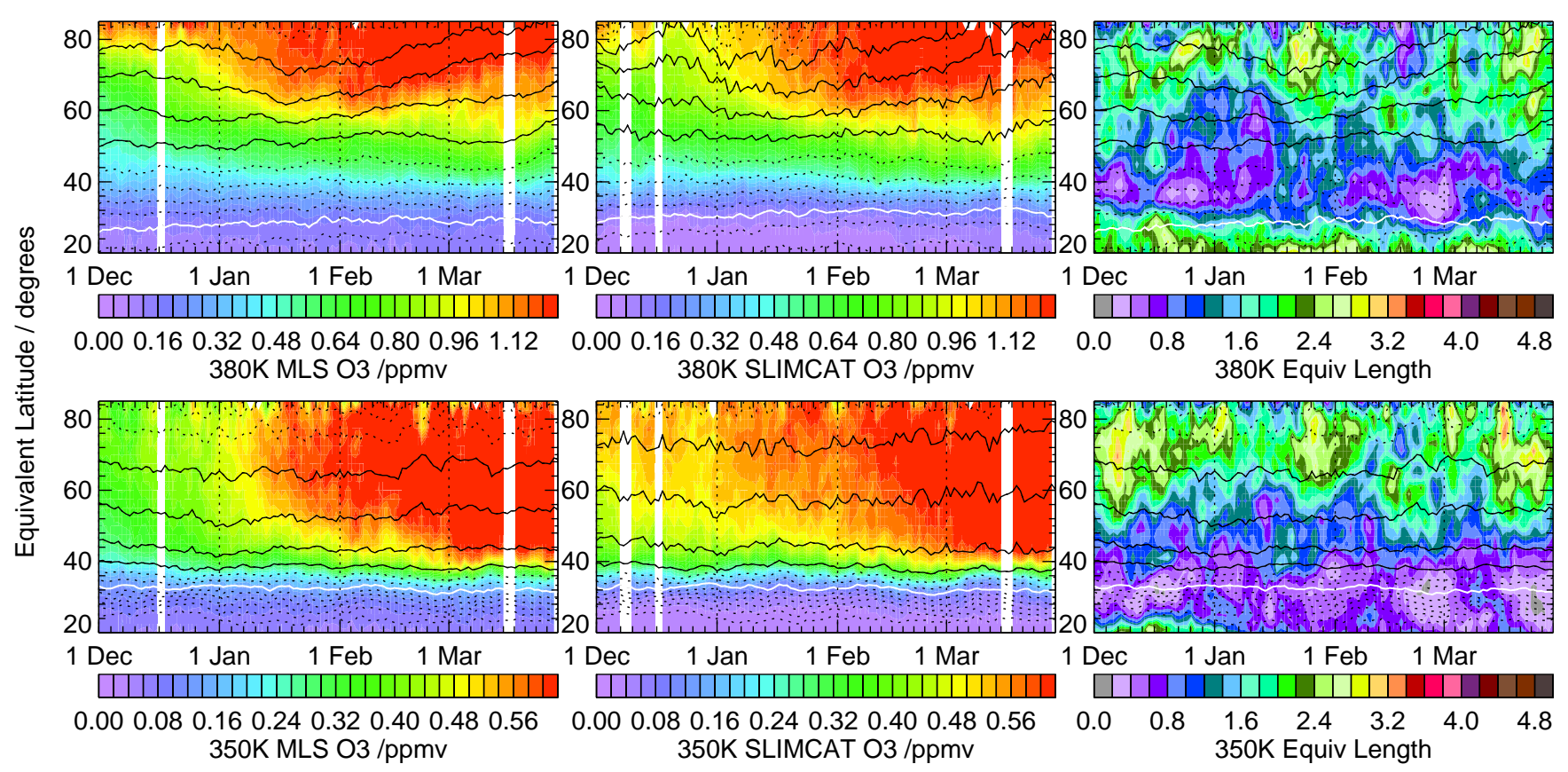

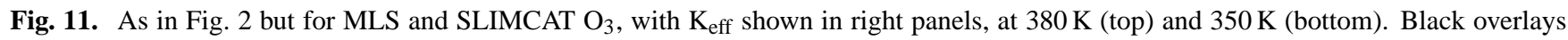
are SPV values, with solid lines indicating those that are in the vortex edge region at higher levels. White overlay is the $4.5 \mathrm{PVU}$ contour, indicative of the dynamical tropopause.

profiles at these levels (Hegglin et al., 2008) are not sufficient to say with confidence whether those subtle variations are real.

Examination of fields before (e.g., at least back to 5 January, not shown) and after (e.g., 26 January, 4 February, Olsen et al., 2008) the breakdown of the stratospheric vortex indicates that ridges drawing low latitude air up into high latitudes were a common, repeated feature of the circulation during much of the 2005-2006 Arctic winter; during each episode, a ridge in the east Atlantic caused low $\mathrm{O}_{3}$ and $\mathrm{HNO}_{3}$ to be drawn into high latitudes (poleward of $60^{\circ} \mathrm{N}$ ), with evidence of quasi-isentropic stratosphere/troposphere exchange in late January and early February (Olsen et al., 2008).

The vertical structure sampled by MLS during this period is shown in Fig. 10, which presents cross-sections of MLS and SLIMCAT $\mathrm{O}_{3}$ in the UTLS along the MLS orbit tracks shown in Fig. 9. Overlaid windspeed contours show the locations of the upper tropospheric and stratospheric jets; the thermal (WMO, temperature gradient) and dynamical $\left(4.5 \times 10^{-6} \mathrm{Km}^{2} \mathrm{~kg}^{-1} \mathrm{~s}^{-1}, 4.5 \mathrm{PVU}\right)$ tropopause locations are also shown. The SLIMCAT fields are sampled at the same horizontal locations as for MLS. The section on the top left shows a track on 17 January that sampled in the midst of the region of low $\mathrm{O}_{3}$ drawn up to high latitudes; the other tracks are to the west of that region on each day. Both sections shown on 17 January cut across the strong high latitude upper tropospheric jet (the "polar jet") accompanying the ridge, as well as the subtropical jet (STJ). As is typical (e.g., Holton et al., 1995; Shepherd, 2002), the tropopause drops sharply poleward of the STJ; over the strong ridge (top left sections), it rises abruptly in the vicinity of the polar jet. In all of the sections, strong $\mathrm{O}_{3}$ gradients correspond closely to the $4.5 \mathrm{PVU}$ dynamical tropopause contour. Double thermal tropopauses are common on the poleward side of the STJ (e.g., Randel et al., 2007), and an extensive region with a double tropopause between the STJ and polar jets is seen in each of the sections to the west of the ridge. On 17 January, the polar jet associated with the ridge lies directly under the stratospheric jet, which defines the southernmost edge of the polar vortex that is shifted off the pole in this direction; the other edge of the vortex is near the pole, and can be identified as the increase in windspeed at the highest latitudes/altitudes shown. On 18 and 19 January, the polar jet has weakened and is largely to the east of the tracks shown (see Fig. 9).

Evidence of both tropospheric and stratospheric intrusions is apparent in each of the $\mathrm{O}_{3}$ fields shown here: On 17 January (top left in Fig. 10), $\mathrm{O}_{3}$ in the area of the ridge had mainly low values characteristic of the troposphere, but a large tongue with stratospheric $\mathrm{O}_{3}$ values extended down and poleward between the STJ and polar jet, resulting in a layered structure with tropospheric $\mathrm{O}_{3}$ values above stratospheric ones. The other sections, taken west of the ridge, have a layer with tropospheric $\mathrm{O}_{3}$ values extending northeastward along the orbit in the region with a double tropopause. Characteristically lower UTLS $\mathrm{O}_{3}$ in profiles with a double tropopause, with a notched profile above the primary (lowest altitude) 
tropopause (e.g., Randel et al., 2007), arises from patterns of $\mathrm{O}_{3}$ transport like those shown here. Despite its coarse vertical resolution (the y-axis tick marks show every retrieval level), most such features seen in the SLIMCAT simulations are represented to some extent in the MLS sections. Because of the coarse spacing, capturing such features can be somewhat fortuitous in MLS, and in SLIMCAT may depend on even small inaccuracies in the driving wind fields that may result in small offsets in the position of modeled features. In some cases (e.g., top left track on 17 January, greater latitudinal extent of high $\mathrm{O}_{3}$ feature), the MLS profiles contain structure that is not as obvious in the SLIMCAT sections, while in other cases (especially intrusions of low $\mathrm{O}_{3}$ on 18 and 19 January), MLS shows a coarser-grain picture of the features seen in SLIMCAT. Olsen et al. (2008) presented a similar analysis of Aura High Resolution Dynamics Limb Sounder (HIRDLS) data and GMI Aura4 simulation results for 26 January through 4 February; HIRDLS has considerably better vertical resolution than MLS, and the orbit tracks are offset between the two instruments. Nevertheless, examination of MLS and SLIMCAT sections on those days (not shown) indicates that MLS captures similar behavior. That both GMI and SLIMCAT (driven by GEOS-4 and ECMWF winds, respectively) accurately represent this UTLS structure is indicative of the high quality of the assimilated meteorological analyses that drive the simulations in the UTLS.

Figure 11 shows $\mathrm{O}_{3}$ from MLS and SLIMCAT along with $\mathrm{K}_{\text {eff }}$ at 380 and $350 \mathrm{~K}$; although at these levels EqL is becoming less appropriate as a "zonal" coordinate since a single circumpolar jet is less representative of the flow (see Fig. 9), these still provide a summary of the average time evolution in a framework consistent with that shown at higher levels (e.g., Figs. 2, 3). At $350 \mathrm{~K}$, the 4.5 PVU contour corresponds to the minimum in $\mathrm{K}_{\mathrm{eff}}$, and MLS and SLIMCAT fields (as well as ACE-FTS, not shown) show very strong $\mathrm{O}_{3}$ gradients across the 4.5 PVU contour, indicating that this contour is an accurate identification of the tropopause as a transport barrier in the EqL average. At $380 \mathrm{~K}$, the strongest transport barrier and $\mathrm{O}_{3}$ gradients are at higher EqLs than the 4.5 PVU contour. $380 \mathrm{~K}$ is the level typically defined as the top boundary of the lowermost stratosphere (e.g., Hoskins, 1991). This transport barrier is thus above the classical definition of the tropopause, and transport with respect to it is determined by the transport characteristics within the tropically controlled transition region (between $\sim 380$ and $\sim 420 \mathrm{~K}$, Rosenlof et al., 1997), where a distinct seasonality in mixing strength between the tropics and extratropics has been observed (Hegglin and Shepherd, 2007). As shown by Haynes and Shuckburgh (2000b) and Allen and Nakamura (2001), the strength of mixing barriers is strongly correlated with the strength of the zonal wind, with higher (lower) windspeeds corresponding to lower (higher) $\mathrm{K}_{\text {eff }}$ values. At $350 \mathrm{~K}$, the strongest winds are associated with the upper tropospheric subtropical jet, which is nearly continuous around the globe near $30^{\circ}$ latitude (which is also near $30^{\circ} \mathrm{EqL}$ in this case), coincident with the location of the 4.5 PVU contour at that level (see Fig. 9). In contrast, the STJ does not extend up to $380 \mathrm{~K}$ at all longitudes, thus at many locations, the strongest winds are associated with the upper tropospheric polar jet and the lowermost extension of the polar night jet (which are both at higher latitudes, near $60^{\circ} \mathrm{N}$, and correspond to higher PV values and thus higher $\mathrm{EqL}$ ); the low $\mathrm{K}_{\text {eff }}$ region seen at $380 \mathrm{~K}$ is indicative of a transport barrier that varies in strength and location with longitude, and is not always representative of the tropopause level. (Larger $\mathrm{K}_{\mathrm{eff}}$ at low latitudes at $380 \mathrm{~K}$ may be related to the zero zonal wind line being shifted north of the equator, where waves breaking along the critical line may cause significant material mixing (Plumb and Mahlman, 1987).)

At both levels, episodic poleward extension of the low $\mathrm{K}_{\text {eff }}$ representing a strong transport barrier is seen starting in late December and continuing into early February - these are the signatures in the EqL average of the local episodes of elevated tropopauses seen in the maps and curtains shown above, which correspond to regions where the STJ is weak and the upper tropospheric polar jet lies directly under the bottom of the stratospheric polar night jet. As apparent in Fig. 9, these episodes are associated with poleward transport of low $\mathrm{O}_{3}$ at the longitudes of the ridges. Because of the complexity of the jet structure (and hence PV and EqL fields) at these levels, the EqL coordinate is not as effective at separating different air masses as in the stratosphere. However, a hint of the poleward transport can be seen in the $\mathrm{O}_{3}$ fields at 380 and $350 \mathrm{~K}$ (especially $350 \mathrm{~K}$ in early February). Comparison with the time evolution at $520 \mathrm{~K}$ in the lower stratosphere (e.g., Figs. 1 and 3) shows a signature of poleward transport outside the vortex in early January that is consistent in MLS, ACE-FTS (not shown) and SLIMCAT, and occurs over the region of elevated tropopause. The deep region of anomalous poleward transport outside the vortex associated with the event implicated in forcing the SSW (Coy et al., 2009) thus extends well into the lower stratosphere. The primary feature of note in the general time evolution of 350 and $380 \mathrm{~K} \mathrm{O}_{3}$ is the increase in $\mathrm{O}_{3}$ via diabatic descent. At $380 \mathrm{~K}$, the tightening of PV contours beginning before mid January, and the appearance of confinement of $\mathrm{O}_{3}$ within these contours (stronger $\mathrm{O}_{3}$ gradients), suggests some influence of the stratospheric vortex extending into the lowermost stratosphere, albeit with less distinct confinement than at higher levels. There appears to be an accelerated increase in $\mathrm{O}_{3}$ in the polar regions at both levels in mid to late January, likely related to the increasingly disturbed and warming vortex above, which is associated with enhanced diabatic descent as the temperatures depart farther from radiative equilibrium. 


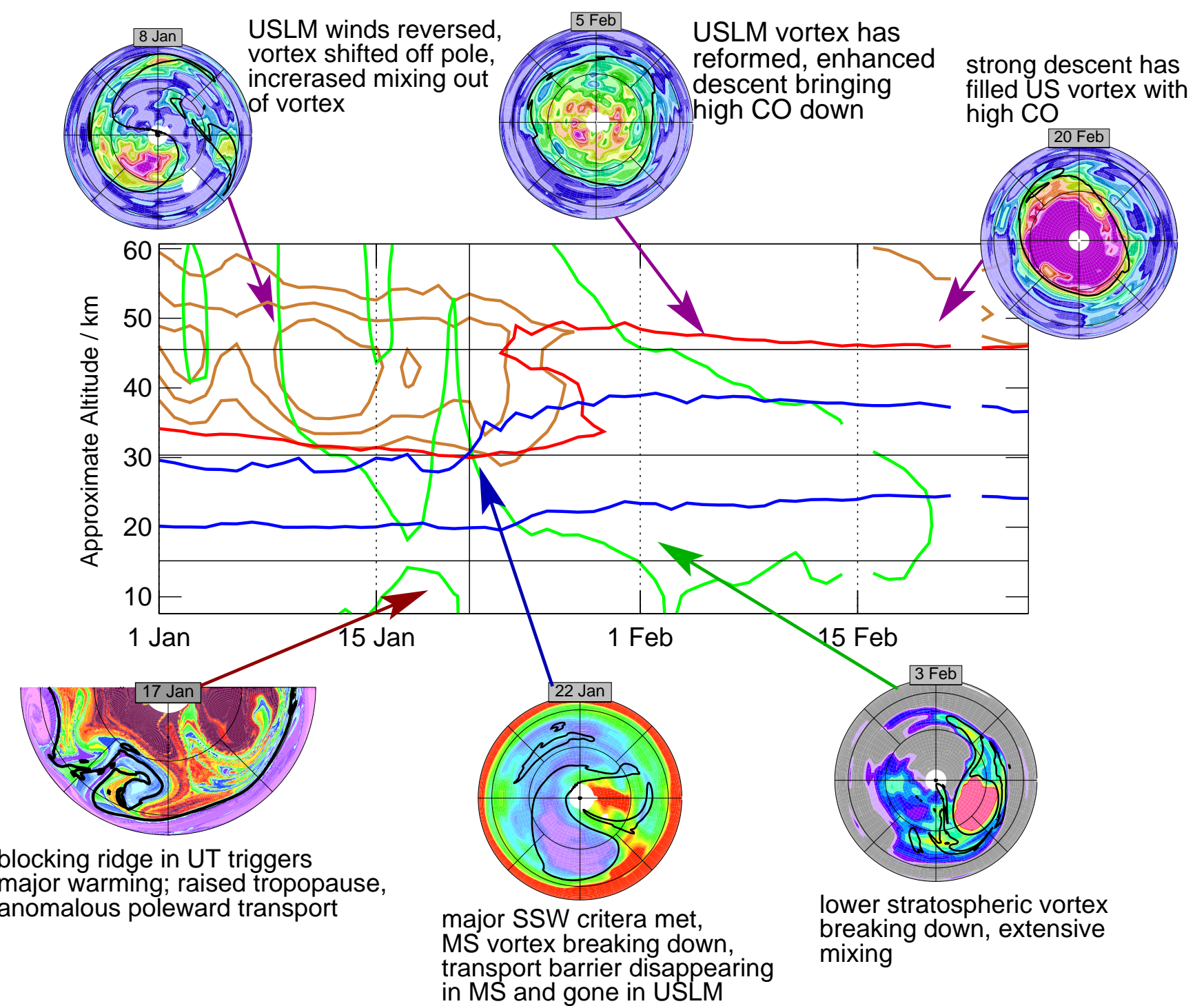

Fig. 12. Schematic of $2006 \mathrm{SSW}$ and corresponding transport. Brown lines show temperature contours in the stratopause region, green lines the zonal mean wind zero contour. Upper stratospheric transport is illustrated by red vortex-averaged CO contour and $2500 \mathrm{~K}$ MLS CO maps on 8 January, 5 February and 20 February. Middle and lower stratospheric transport is illustrated by blue $\mathrm{N}_{2} \mathrm{O}$ contours, an $850 \mathrm{~K}$ MLS $\mathrm{N}_{2} \mathrm{O}$ map on 22 January, and a $520 \mathrm{~K} \mathrm{MLS} \mathrm{H}_{2} \mathrm{O}$ map on 3 February. UTLS transport is illustrated by a $380 \mathrm{~K}$ RT O 3 map on 17 January.

\section{Summary and conclusions}

The January 2006 event was the first major SSW for which globally distributed long-lived trace gas data are available covering the lowermost stratosphere through the lower mesosphere. It was also one of the strongest and most prolonged SSWs on record. We have used Aura MLS data, augmented by fields from ACE-FTS, along with a state-ofthe-art CTM and assimilated meteorological analyses, to detail three-dimensional transport from the UTLS through the USLM during the $2006 \mathrm{SSW}$, and to help assess the consistency of dynamical fields from operational assimilation systems with the observed transport. Figure 12 summarizes the evolution of the SSW in relation to transport reflected in the MLS data.

The SSW was apparently triggered by waves propagating upward from a strong upper tropospheric ridge just after mid-January (Coy et al., 2009). This ridge was accompanied by an elevated tropopause, and strong poleward transport in a deep region of the UTLS, at some levels leading to quasi-isentropic stratosphere/troposphere exchange. MLS trace gases in the UTLS show a deep layer extending from below the tropopause through the lower stratosphere with enhanced poleward transport of low $\mathrm{O}_{3}$ and $\mathrm{HNO}_{3}$ outside the vortex. These patterns of transport result in lamination 
in the trace gases in the levels around the tropopause, typically in a region with a double tropopause, resulting from both intrusions of stratospheric air into the troposphere and tropospheric air into the stratosphere.

The stratospheric vortex broke apart from the top down, with $\mathrm{K}_{\mathrm{eff}}$ calculations showing the complete disappearance of the polar vortex transport barrier in the upper stratosphere just after mid-January, and by late January in the middle stratosphere. At these levels, the vortex breakdown was very rapid, occurring over a few days. The evolution of PV and the $\mathrm{K}_{\mathrm{eff}}$ calculations show a somewhat more gradual and later breakdown in the lower stratosphere, with the transport barrier shrinking to a small area in mid-February. $\mathrm{K}_{\mathrm{eff}}$, and the trace gas evolution, shows a small remnant of the vortex persisting throughout the winter below the middle stratosphere ( $\sim 850 \mathrm{~K}$ and below).

Consistent with the disappearance of the transport barrier, trace gases measured by MLS $\left(\mathrm{CO}\right.$ and $\mathrm{H}_{2} \mathrm{O}$, and $\mathrm{N}_{2} \mathrm{O}$ in/below the middle stratosphere) and ACE-FTS show the signature of strong mixing, with values characteristic of low and midlatitudes extending to the polar regions and extremely weak tracer gradients throughout the hemisphere. In the middle and lower stratosphere, small remnants with high $\mathrm{H}_{2} \mathrm{O} /$ low $\mathrm{N}_{2} \mathrm{O}$ values characteristic of the pre-SSW vortex lingered into the recovery.

In the upper stratosphere to lower mesosphere, the vortex very quickly reformed and strengthened, becoming larger and stronger than before the SSW by early February. High $\mathrm{CO}$ values in the vortex, present before the warming from the mesosphere to the middle stratosphere, were mixed with lower latitude air with orders of magnitude less $\mathrm{CO}$, resulting in very low $\mathrm{CO}$ at all latitudes during the SSW. As the vortex reformed and very strong diabatic descent developed (e.g., Siskind et al., 2007; Manney et al., 2008b), high CO was once again transported from the mesosphere into the confined upper stratospheric vortex, echoing the pattern of descent typically seen in fall/early winter.

In the middle and lower stratosphere, the vortex and transport barrier remained weak after the SSW for the duration of the winter. Trace gas gradients remained correspondingly weak, with (especially in the lower stratosphere) lingering vortex remnants with pre-SSW trace gas values enclosed within a larger region of weak, but distinct, gradients associated with the weak reformed vortex.

The evolution of the trace gas distributions is consistent with that of the dynamical fields ( $\mathrm{PV}, \mathrm{K}_{\mathrm{eff}}$ ) in the meteorological analyses shown here, with agreement being somewhat weaker in the upper stratosphere/lower mesosphere in the period after the SSW, consistent with deficiencies reported by Manney et al. (2008b) in the operational assimilated analyses during that period.

The SLIMCAT CTM also does a very good job of simulating transport during the SSW in the UTLS through the middle stratosphere, with differences only in detail, such as slightly too strong descent in the lower stratosphere, and not enough mixing in the middle stratosphere. In the upper stratosphere and lower mesosphere, however, the SLIMCAT simulation failed to capture the strong descent of mesospheric $\mathrm{CO}$ and $\mathrm{H}_{2} \mathrm{O}$ values into the reformed vortex. The descent is seen to begin much later than that observed, and at that point becomes too strong. Radiation calculations based on MLS versus ECMWF temperatures show that strong biases in ECMWF temperatures result in much weaker descent immediately after the SSW, followed by descent becoming stronger than that derived from MLS temperatures about a month later. This pattern is consistent with the most obvious failings of the SLIMCAT simulation in the USLM. These deficiencies in the USLM may be exacerbated by the proximity of this region to the model top and by differences in the vortex structure/horizontal winds at these levels. A simulation with a different CTM driven with GEOS-4 (which has opposite temperature biases to ECMWF in the period following the SSW) winds shows too rapid descent into the vortex following the SSW. Thus, the evidence indicates that the failings of CTMs in the upper stratosphere result primarily from corresponding inaccuracies in the wind and temperature fields used to drive them.

The above results provide the first detailed, comprehensive observational picture of transport during a major SSW covering the upper troposphere throughout the lower mesosphere, and an assessment of the representation of that transport in a state-of-the-art CTM. Recent satellite datasets, such as the MLS and ACE-FTS data used here, are critical to such assessments, which in turn are essential to improving our data assimilation and modeling capabilities.

Acknowledgements. Thanks to the MLS team, especially Lucien Froidevaux, Brian W. Knosp, and Robert P. Thurstans, and the ACE Team, especially Sean McLeod and Ryan Hughes, for their continuing support and assistance. Thanks to the GMAO and ECMWF for producing/providing their assimilated data products, and to Steven Pawson for helpful discussions and comments; thanks to Susan E. Strahan for making available and providing advice on the GMI Aura4 simulation, and to Martyn Chipperfield for the SLIMCAT model. We appreciate the helpful comments of the two anonymous reviewers. Research at the Jet Propulsion Laboratory, California Institute of Technology, was done under contract with the National Aeronautics and Space Administration. Funding for the ACE mission was provided primarily by the Canadian Space Agency and the Natural Sciences and Engineering Research Council of Canada. Ian MacKenzie is funded by the UK Natural Environment Research Council.

Edited by: W. Lahoz

\section{References}

Allen, D. R. and Nakamura, N.: A seasonal climatology of effective diffusivity in the stratosphere, J. Geophys. Res., 106, 7917-7935, 2001.

Allen, D. R. and Nakamura, N.: Dynamical reconstruction of the record low column ozone over Europe on 30 November 1999 , 
Geophys. Res. Lett., 29, 1362, doi:10.1029/2002GL014 935, 2002.

Allen, D. R., Stanford, J. L., López-Valverde, M. A., Nakamura, N., Lary, D. J., Douglass, A. R., Cerniglia, M. C., Remedios, J. J., and Taylor, F. W.: Observations of middle atmosphere $\mathrm{CO}$ from the UARS ISAMS during the early northern winter 1991/1992, J. Atmos. Sci., 56, 563-583, 1999.

Allen, D. R., Stanford, J. L., , Nakamura, N., López-Valverde, M. A., López-Puertas, M., Taylor, F. W., and Remedios, J. J.: Antarctic polar descent and planetary wave activity observed in ISAMS CO from April to July 1992, Geophys. Res. Lett., 27, 665-668, 2000.

Allen, D. R., Coy, L., Eckermann, S. D., McCormack, J. P., Manney, G. L., Hogan, T. F., and Kim, Y.-J.: NOGAPS-ALPHA Simulations of the 2002 Southern Hemisphere Major Warming, Mon. Weather Rev., 134, 498-518, 2006.

Bernath, P. F., McElroy, C. T., Abrams, M. C., et al.: Atmospheric Chemistry Experiment (ACE): mission overview, Geophys. Res. Lett., 32, L15S01, doi:10.1029/2005GL022386, 2005.

Bloom, S. C., Takacs, L. L., da Silva, A. M., and Ledvina, D.: Data Assimilation Using Incremental Analysis Updates, Mon. Weather Rev., 124, 1256-1271, 1996.

Bloom, S. C., da Silva, A., Dee, D., et al.: The Goddard Earth Observing Data Assimilation System, GEOS DAS Version 4.0.3: Documentation and Validation, Tech. Rep. 104606 V26, NASA, 2005.

Boone, C. D., Nassar, R., Walker, K. A., Rochon, Y., McLeod, S. D., Rinsland, C. P., and Bernath, P. F.: Retrievals for the Atmospheric Chemistry Experiment Fourier-Transform Spectrometer, Appl. Optics, 44, 7218-7231, 2005.

Braathen, G., Grunow, K., Kivi, R., et al.: Joint WMO/EU Arctic ozone bulletin, winter/spring summary, Tech. Rep. 2006-1, World Meteorological Organization/European Ozone Research Coordinating Unit, available at http://www.wmo.int/pages/prog/ arep/gaw/ozone/index.html, 2006.

Briegleb, B. P.: Delta-Eddington approximation for solar radiation in the NCAR Community Climate Model, J. Geophys. Res., 97, 7603-7612, 1992a.

Briegleb, B. P.: Longwave band model for thermal radiation in climate studies, J. Geophys. Res., 97, 11475-11485, 1992b.

Carleer, M. R., Boone, C. D., Walker, K. A., Bernath, P. F., Strong, K., Sica, R. J., Randall, C. E., Vömel, H., Kar, J., Höpfner, M., Milz, M., von Clarmann, T., Kivi, R., Valverde-Canossa, J., Sioris, C. E., Izawa, M. R. M., Dupuy, E., McElroy, C. T., Drummond, J. R., Nowlan, C. R., Zou, J., Nichitiu, F., Lossow, S., Urban, J., Murtagh, D., and Dufour, D. G.: Validation of water vapour profiles from the Atmospheric Chemistry Experiment (ACE), Atmos. Chem. Phys. Discuss., 8, 4499-4559, 2008, http://www.atmos-chem-phys-discuss.net/8/4499/2008/.

Chipperfield, M. P.: Multiannual simulations with a threedimensional chemical transport model, J. Geophys. Res., 104, 1781-1805, 1999.

Chipperfield, M. P.: New version of the TOMCAT/SLIMCAT offline chemical transport model: Intercomparison of stratospheric tracer experiments, Q. J. R. Meteorol. Soc., 132, 1179-1203, 2006.

Chipperfield, M. P., Lee, A. M., and Pyle, J. A.: Model calculations of ozone depletion in the Arctic polar vortex for 1991/92 to 1994/95, Geophys. Res. Lett., 23, 559-562, 1996.
Clerbaux, C., George, M., Turquety, S., et al.: CO measurements from the ACE-FTS satellite instrument: data analysis and validation using ground-based, airborne and spaceborne observations, Atmos. Chem. Phys., 8, 2569-2594, 2008,

http://www.atmos-chem-phys.net/8/2569/2008/.

Coy, L., Eckermann, S., and Hoppel, K.: Planetary wave breaking and tropospheric forcing as seen in the stratospheric sudden warming of 2006, J. Atmos. Sci., 66, 495-507, 2009.

De Mazière, M., Vigouroux, C., Bernath, P. F., Baron, P., Blumenstock, T., Boone, C., Brogniez, C., Catoire, V., Coffey, M., Duchatelet, P., Griffith, D., Hannigan, J., Kasai, Y., Kramer, I., Jones, N., Mahieu, E., Manney, G. L., Piccolo, C., Randall, C., Robert, C., Senten, C., Strong, K., Taylor, J., Ttard, C., Walker, K. A., and Wood, S.: Validation of ACE-FTS v2.2 methane profiles from the upper troposphere to the lower mesosphere, Atmos. Chem. Phys., 8, 2421-2435, 2008,

http://www.atmos-chem-phys.net/8/2421/2008/.

Dupuy, E., Walker, K. A., Kar, J., et al.: Validation of ozone measurements from the Atmospheric Chemistry Experiment (ACE), Atmos. Chem. Phys., 9, 287-343, 2009, http://www.atmos-chem-phys.net/9/287/2009/.

Fairlie, T. D. A., Fisher, M., and O'Neill, A.: The development of narrow baroclinic zones and other small-scale structure in the stratosphere during simulated major warmings, Q. J. Roy. Meteorol. Soc., 116, 287-315, 1990.

Feng, W., Chipperfield, M. P., Roscoe, H. K., Remedios, J. J., Waterfall, A. M., Stiller, G. P., Glatthor, N., Höpfner, M., and Wang, D.-Y.: Three-dimensional model study of the Antarctic ozone hole in 2002 and comparison with 2000, J. Atmos. Sci., 62, 822837, 2005.

Fisher, M., O'Neill, A., and Sutton, R.: Rapid descent of mesospheric air into the stratospheric polar vortex, Geophys. Res. Lett., 20, 1267-1270, 1993.

Flocke, F., Herman, R. L., Salawitch, R. J., et al.: An examination of chemistry and transport processes in the tropical lower stratosphere using observations of long-lived and short-lived compounds obtained during STRAT and POLARIS, J. Geophys. Res., 104, 26625-26642, 1999.

Froidevaux, L., Jiang, Y. B., Lambert, A., et al.: Validation of EOS MLS stratospheric ozone measurements, J. Geophys. Res., 113, D15S20, doi:10.1029/2007JD008771, 2008.

Haynes, P. and Shuckburgh, E.: Effective diffusivity as a diagnostic of atmospheric transport 1. Stratosphere, J. Geophys. Res., 105, 22777-22794, 2000a.

Haynes, P. and Shuckburgh, E.: Effective diffusivity as a diagnostic of atmospheric transport 2. Troposphere and lower stratosphere, J. Geophys. Res., 105, 22795-22810, 2000b.

Hegglin, M. I. and Shepherd, T. G.: $\mathrm{O}_{3}-\mathrm{N}_{2} \mathrm{O}$ correlations from the Atmospheric Chemistry Experiment: Revisiting a diagnostic of transport and chemistry in the stratosphere, J. Geophys. Res., 112, D19301, doi:10.1029/2006JD008281, 2007.

Hegglin, M. I., Boone, C. D., Manney, G. L., Shepherd, T. G., Walker, K. A., Bernath, P. F., Daffer, W. H., Hoor, P., and Schiller, C.: Validation of ACE-FTS satellite data in the upper troposphere/lower stratosphere (UTLS) using non-coincident measurements, Atmos. Chem. Phys., 8, 1483-1499, 2008, http://www.atmos-chem-phys.net/8/1483/2008/.

Hegglin, M. I., Boone, C. D., Manney, G. L., and Walker, K. A.: A global view of the extratropical tropopause transition layer from 
Atmospheric Chemistry Experiment Fourier Transform Spectrometer $\mathrm{O}_{3}, \mathrm{H}_{2} \mathrm{O}$, and $\mathrm{CO}$, J. Geophys. Res., 114, D00B11, doi:10.1029/2008JD009984, 2009.

Hegglin, M. I., Brunner, D., Wernli, H., Schwierz, C., Martius, O., Hoor, P., Fischer, H., Parchatka, U., Spelten, N., Schiller, C., Krebsbach, M., Weers, U., Staehelin, J., and Peter, Th.: Tracing troposphere-to-stratosphere transport above a mid-latitude deep convective system, Atmos. Chem. Phys., 4, 741-756, 2004, http://www.atmos-chem-phys.net/4/741/2004/.

Hoffmann, P., Singer, W., Keuer, D., Hocking, W. K., Kunze, M., and Murayama, Y.: Latitudinal and longitudinal variability of mesospheric winds and temperatures during stratospheric warming events, J. Atmos. Solar-Terr. Phys., 69, 2355-2366, 2007.

Holton, J. R., Haynes, P. H., McIntyre, M. E., Douglass, A. R., Rood, R. B., and Pfister, L.: Stratosphere-Troposphere exchange, Rev. Geophys., 33, 403-439, 1995.

Hoskins, B. J.: Towards a PV- $\theta$ view of the general circulation, Tellus, 43AB, 27-35, 1991.

Jin, J. J., Semeniuk, K., Beagley, S. R., Fomichev, V. I., Jonsson, A. I., McConnell, J. C., Urban, J., Murtagh, D., Manney, G. L., Boone, C. D., Bernath, P. F., Walker, K. A., Barret, B., Ricaud, P., and Dupuy, E.: Comparison of CMAM simulations of carbon monoxide $(\mathrm{CO})$, nitrous oxide $\left(\mathrm{N}_{2} \mathrm{O}\right)$, and methane $\left(\mathrm{CH}_{4}\right)$ with observations from Odin/SMR, ACE-FTS, and Aura/MLS, Atmos. Chem. Phys., 9, 3233-3252, 2009,

http://www.atmos-chem-phys.net/9/3233/2009/.

Keil, M., Jackson, D. R., and Hort, M. C.: The January 2006 low ozone event over the UK, Atmos. Chem. Phys., 7, 961-972, 2007, http://www.atmos-chem-phys.net/7/961/2007/.

Konopka, P., Grooß, J.-U., Hoppel, K. W., Steinhorst, H.-M., and Müller, R.: Mixing and chemical ozone loss during and after the Antarctic polar vortex major warming in September 2002, J. Atmos. Sci., 62, 848-859, 2005.

Lahoz, W. A., O’Neill, A., Carr, E. S., et al.: Three-dimensional evolution of water vapour distributions in the northern hemisphere stratosphere as observed by the Microwave Limb Sounder, J. Atmos. Sci., 51, 2914-2930, 1994.

Lambert, A., Read, W. G., Livesey, N. J., et al.: Validation of the Aura Microwave Limb Sounder stratospheric water vapor and nitrous oxide measurements, J. Geophys. Res., 113, D24S36, doi:10.1029/2007JD008724, 2007.

Leovy, C. B., Sun, C., Hitchman, M. H., Remsberg, E. E., Russell, III, J. M., Gordley, L. L., Gille, J. C., and Lyjak, L. V.: Transport of ozone in the middle stratosphere: Evidence for planetary wave breaking, J. Atmos. Sci., 42, 230-244, 1985.

Livesey, N. J., Read, W. G., Lambert, A., et al.: MLS Version 2.2 Level 2 data quality and description document, Tech. Rep. JPL D-33509, Jet Propulsion Laboratory, available at http://mls.jpl. nasa.gov, 2007.

Livesey, N. J., Filipiak, M. J., Froidevaux, L., et al.: Validation of Aura Microwave Limb Sounder $\mathrm{O}_{3}$ and $\mathrm{CO}$ observations in the upper troposphere and lower stratosphere, J. Geophys. Res., 113, D15S02, doi:10.1029/2007JD008805, 2008.

Manney, G. L., Farrara, J. D., and Mechoso, C. R.: Simulations of the February 1979 stratospheric sudden warming: Model comparisons and three-dimensional evolution, Mon. Weather Rev., 122, 1115-1140, 1994a.

Manney, G. L., Zurek, R. W., O'Neill, A., and Swinbank, R.: On the motion of air through the stratospheric polar vortex, J. Atmos.
Sci., 51, 2973-2994, 1994b.

Manney, G. L., Zurek, R. W., O’Neill, A., Swinbank, R., Kumer, J. B., Mergenthaler, J. L., and Roche, A. E.: Stratospheric warmings during February and March 1993, Geophys. Res. Lett., 21, 813-816, 1994c.

Manney, G. L., Froidevaux, L., Waters, J. W., , Gille, J. C., Zurek, R. W., Kumer, J. B., Mergenthaler, J. L., Roche, A. E., O’Neill, A., and Swinbank, R.: Formation of low-ozone pockets in the middle stratospheric anticyclone during winter, J. Geophys. Res., 100, 13939-13950, 1995.

Manney, G. L., Bird, J. C., Donovan, D. P., Duck, T. J., Whiteway, J. A., Pal, S. R., and Carswell, A. I.: Modeling ozone laminae in ground-based Arctic wintertime observations using trajectory calculations and satellite data, J. Geophys. Res., 103, 5797-5814, 1998.

Manney, G. L., Lahoz, W. A., Swinbank, R., O’Neill, A., Connew, P. M., and Zurek, R. W.: Simulation of the December 1998 stratospheric major warming, Geophys. Res. Lett., 26, 2733 2736, 1999a.

Manney, G. L., Michelsen, H. A., Santee, M. L., Gunson, M. R., Irion, F. W., Roche, A. E., and Livesey, N. J.: Polar vortex dynamics during spring and fall diagnosed using trace gas observations from the Atmospheric Trace Molecule Spectroscopy instrument, J. Geophys. Res., 104, 18841-18866, 1999 b.

Manney, G. L., Krüger, K., Sabutis, J. L., Sena, S. A., and Pawson, S.: The remarkable 2003-2004 winter and other recent warm winters in the Arctic stratosphere since the late 1990s, J. Geophys. Res., 110, D04107, doi:10.1029/2004JD005367, 2005a.

Manney, G. L., Sabutis, J. L., Allen, D. R., Lahoz, W. A., Scaife, A. A., Randall, C. E., Pawson, S., Naujokat, B., and Swinbank, R.: Simulations of dynamics and transport during the September 2002 Antarctic major warming, J. Atmos. Sci., 62, 690-707, 2005b.

Manney, G. L., Daffer, W. H., Zawodny, J. M., et al.: Solar Occultation Satellite Data and Derived Meteorological Products: Sampling Issues and Comparisons with Aura MLS, J. Geophys. Res. 112, D24S50, doi:10.1029/2007JD008709, 2007.

Manney, G. L., Daffer, W. H., Strawbridge, K. B., Walker, K. A., Boone, C. D., Bernath, P. F., Kerzenmacher, T., Schwartz, M. J., Strong, K., Sica, R. J., Krüger, K., Pumphrey, H. C., Lambert, A., Santee, M. L., Livesey, N. J., Remsberg, E. E., Mlynczak, M. G., and Russell III, J. R.: The high Arctic in extreme winters: vortex, temperature, and MLS and ACE-FTS trace gas evolution, Atmos. Chem. Phys., 8, 505-522, 2008a, http://www.atmos-chem-phys.net/8/505/2008/.

Manney, G. L., Kruger, K., Pawson, S., et al.: The evolution of the stratopause during the 2006 major warming: Satellite Data and Assimilated Meteorological Analyses, J. Geophys. Res., 113, D11115, doi:10.1029/2007JD009097, 2008b.

Minschwaner, K., Carver, R. W., Briegleb, B. P., and Roche, A. E.: Infrared radiative forcing and atmospheric lifetimes of trace species based on observations from UARS, J. Geophys. Res., 103, 23243-23253, 1998.

Olsen, M. A., Douglass, A. R., Newman, P. A., Gille, J. C., Nardi, B., Yudin, V. A., Kinnison, D. E., and Khosravi, R.: HIRDLS observations and simulation of a lower stratospheric intrusion of tropical air to high latitudes, Geophys. Res. Lett., 35, L21813, doi:10.1029/2008GL035514, 2008.

O’Neill, A., Grose, W. L., Pope, V. D., McClean, H., and Swinbank, 
R.: Evolution of the stratosphere during northern winter 1991/92 as diagnosed from U.K. Meteorological Office analyses, J. Atmos. Sci., 51, 2800-2817, 1994.

Pancheva, D., Mukhtarov, P., Mitchell, N. J., Merzlyakov, E., Smith, A. K., Andonov, B., Singer, W., Hocking, W., Meek, C., Manson, A., and Murayama, Y.: Planetary waves in coupling the stratosphere and mesosphere during the major stratospheric warming in 2003/2004, J. Geophys. Res., 113, D12105, doi:10.1029/2007JD009011, 2008.

Plumb, R. A. and Mahlman, J. D.: The zonally averaged transport characteristics of the GFDL general circulation/transport model, J. Atmos. Sci., 44, 298-327, 1987.

Pumphrey, H. C., Filipiak, M. J., Livesey, N. J., et al.: Validation of the Aura Microwave Limb Sounder stratospheric and mesospheric CO measurements, J. Geophys. Res., 112, D24S38, doi:10.1029/2007JD008723, 2007.

Randall, C. E., Manney, G. L., Allen, D. R., Bevilacqua, R. M., Trepte, C., Lahoz, W. A., and O'Neill, A.: Reconstruction and Simulation of Stratospheric Ozone Distributions During the 2002 Austral Winter, J. Atmos. Sci., 62, 748-764, 2005.

Randall, C. E., Harvey, V. L., Singleton, C. S., Bernath, P. F., Boone, C. D., and Kozyra, J. U.: Enhanced $\mathrm{NO}_{x}$ in 2006 linked to strong upper stratospheric Arctic vortex, Geophys. Res. Lett., 33, L18811, doi:10.1029/2006GL027160, 2006.

Randel, W. J., Seidel, D. J., and Pan, L.: Observational characteristics of double tropopauses, J. Geophys. Res., 112, D07309, doi:10.1029/2006JD00794, 2007.

Reinecker, M. M., Suarez, M. J., Todling, R., et al.: The GEOS5 Data Assimilation System: A Documentation of GEOS-5.0, Tech. Rep. 104606 V27, NASA, 2008.

Rosenlof, K. H., Tuck, A. F., Kelly, K. K., III, J. M. R., and McCormick, M. P.: Hemispheric asymmetries in water vapor and inferences about transport in the lower stratosphere, J. Geophys. Res., 102, 13213-13234, 1997.

Santee, M. L., Manney, G. L., Froidevaux, L., Read, W. G., Livesey, N. J., and Lambert, A.: Trace gas evolution in the lowermost stratosphere from Aura Microwave Limb Sounder measurements: Subvortex processing and transport, J. Geophys. Res., in preparation, 2009.

Santee, M. L., Lambert, A., Read, W. G., et al.: Validation of the Aura Microwave Limb Sounder $\mathrm{HNO}_{3}$ measurements, J. Geophys. Res., 112, D24S40, doi:10.1029/2007JD008721, 2007.

Santee, M. L., MacKenzie, I. A., Manney, G. L., et al.: A study of stratospheric chlorine partitioning based on new satellite measurements and modeling, J. Geophys. Res., 113, D12307, doi:10.1029/2007JD009057, 2008.

Schwartz, M. J., Lambert, A., Manney, G. L., et al.: Validation of the Aura Microwave Limb Sounder temperature and geopotential height measurements, J. Geophys. Res., 113, D15S11, doi:10.1029/2007JD008783, 2008.

Shepherd, T. G.: Issues in stratosphere-troposphere coupling, J. Meteor. Soc. Japan, 80, 769-792, 2002.
Shepherd, T. G.: Transport in the middle atmosphere, J. Meteorol. Soc. Japan, 85B, 165-191, 2007.

Simmons, A. J., Hortal, M., Kelly, G., McNally, A., Untch, A., and Uppala, S.: ECMWF analyses and forecasts of stratospheric winter polar vortex break-up: September 2002 in the southern hemisphere and related events, J. Atmos. Sci., 62, 668-689, 2005.

Siskind, D. E., Eckermann, S. D., Coy, L., and McCormack, J. P.: On recent interannual variability of the Arctic winter mesosphere: Implications for tracer descent, Geophys. Res. Lett., 34, L09806, doi:10.1029/2007GL029293, 2007.

Strahan, S. E., Duncan, B. N., and Hoor, P.: Observationally derived transport diagnostics for the lowermost stratosphere and their application to the GMI chemistry and transport model, Atmos. Chem. Phys., 7, 2435-2445, 2007, http://www.atmos-chem-phys.net/7/2435/2007/.

Strong, K., Wolff, M. A., Kerzenmacher, T. E., et al.: Validation of ACE-FTS N2O measurements, Atmos. Chem. Phys., 8, 47594786, 2008, http://www.atmos-chem-phys.net/8/4759/2008/.

Sutton, R. T., MacLean, H., Swinbank, R., O’Neill, A., and Taylor, F. W.: High-resolution stratospheric tracer fields estimated from satellite observations using Lagrangian trajectory calculations, J. Atmos. Sci., 51, 2995-3005, 1994.

Swinbank, R. and O'Neill, A.: A stratosphere-troposphere data assimilation system, Mon. Weather Rev., 122, 686-702, 1994.

Swinbank, R., Ingleby, N. B., Boorman, P. M., and Renshaw, R. J.: A 3D variational data assimilation system for the stratosphere and troposphere, Tech. Rep. 71, Met Office Numerical Weather Prediction Forecasting Research Scientific Paper, 2002.

Swinbank, R., Keil, M., Jackson, D. R., and Scaife, A. A.: Stratospheric Data Assimilation at the Met Office - progress and plans, in: ECMWF workshop on Modelling and Assimilation for the Stratosphere and Tropopause 23-26-June, 2003, ECMWF, 2004

Tan, W. W., Geller, M. A., Pawson, S., and da Silva, A.: A case study of excessive subtropical transport in the stratosphere of a data assimilation system, J. Geophys. Res., 109, D11102, doi:10.1029/2003JD004057, 2004.

Thompson, D. W. J., Baldwin, M. P., and Solomon, S.: Stratosphere/troposphere coupling in the Southern Hemisphere, J. Atmos. Sci., 62, 708-715, 2005.

Untch, A., Miller, M., Hortal, M., Buizza, R., and Janssen, P.: Towards a global meso-scale model: The high resolution system T799L91 and T399L62 EPS, ECMWF Newsletter, 108, 6-13, 2006.

Waters, J. W., Froidevaux, L., Harwood, R. S., et al.: The Earth Observing System Microwave Limb Sounder (EOS MLS) on the Aura satellite, IEEE Trans. Geosci. Remote Sens., 44, 10751092, 2006.

WMO: Scientific assessment of stratospheric ozone depletion: 2006, U. N. Environ. Program, Geneva, Switzerland, 2007.

Wu, W.-S., Purser, R. J., and Parish, D. F.: Three-dimensional variational analyses with spatially inhomogeneous covariances, Mon. Weather Rev., 130, 2905-2916, 2002. 